\title{
An Evaluation of Three Models Designed for Siting Wind Turbines in Areas of Complex Terrain
}

\author{
J. C. Barnard
}

June 1990

Prepared for the U.S. Department of Energy under Contract DE-AC06-76RLO 1830

Pacific Northwest Laboratory Operated for the U.S. Department of Energy by Battelle Memorial Institute 


\title{
DISCLAIMER
}

This report was prepared as an account of work sponsored by an agency of the United States Government. Neither the United States Government nor any agency thereof, nor Battelle Memorial Institute, nor any of their employees, makes any warranty, expressed or implied, or assumes any legal liability or responsibility for the accuracy, completeness, or usefulness of any information, apparatus, product, or process disclosed, or represents that its use would not infringe privately owned rights. Reference herein to any specific commercial product, process, or service by trade name, trademark, manufacturer, or otherwise, does not necessarily constitute or imply its endorsement, recommendation, or favoring by the United States Covernment or any agency thereof, or Battelle Memorial Institute. The views and opinions of authors expressed herein do not necessarily state or reflect those of the United States Covernment or any agency thereof.

\author{
PACIFIC NORTHWEST LABORATORY \\ operated by \\ BATTELLE MEMORIAL INSTITUTE \\ for the \\ UNITED STATES DEPARTMENT OF ENERGY \\ under Contract DE-ACO6-76RLO 1830
}

Printed in the United States of America

Available to DOE and DOE contractors from the

Office of Scientific and Technical Information, P.O. Box 62, Oak Ridge, TN 37831; prices available from (615) 576-8401. FTS 626-8401.

Available to the public from the National Technical Information Service, U.S. Department of Commerce, 5285 Port Royal Rd., Springfield, VA 22161.

NTIS Price Codes, Microfiche A01

Printed Copy

\begin{tabular}{ccccc}
\hline Price Code & Page Range & & Price Code & Page Range \\
\cline { 5 - 5 } \cline { 4 - 5 } A02 & $1-10$ & & A15 & $326-350$ \\
A03 & $11-50$ & & A16 & $351-375$ \\
A04 & $51-75$ & & A17 & $376-400$ \\
A05 & $76-100$ & & A18 & $401-425$ \\
A06 & $101-125$ & A19 & $426-450$ \\
A07 & $126-150$ & A20 & $451-475$ \\
A08 & $151-175$ & & A21 & $476-500$ \\
A09 & $176-200$ & & A22 & $501-525$ \\
A10 & $201-225$ & A23 & $526-550$ \\
A11 & $226-250$ & A24 & $551-575$ \\
A12 & $251-275$ & A25 & $576-600$ \\
A13 & $276-300$ & A99 & $601-U p$ \\
A14 & $301-325$ & &
\end{tabular}


PNL-7357

UC -261

AN EVALUATION OF THREE MODELS

DESIGNED FOR SITING WIND TURBINES

IN AREAS OF COMPLEX TERRAIN

J. C. Barnard

June 1990

Prepared for the U.S. Department of Energy under Contract DE-ACO6-76RLO 1830

Pacific Northwest Laboratory

Richland, Washington 99352 


\section{$\underline{\text { SUMMARY }}$}

The aim of this study was to compare the ability of three micrositing models to simulate the wind flow in complex terrain. One of these models, NOABL, is a mass-consistent model while the other two, MS3DJH/3R and BZ, are descendants of Jackson-Hunt $(\mathrm{J}-\mathrm{H})$ theory. All three models were applied to two areas of complex terrain, Askervein Hill in Scotland and Altamont Pass in California. Askervein $\mathrm{Hill}$ is an isolated hill of moderate slope surrounded by a flat plain. In marked contrast, the terrain of Altamont Pass is very complicated and is aptly described as being very hilly. Over each modeled area, wind measurements taken from a relatively dense network of anemometry were used to assess the performance of the models by comparing these data to the model-derived winds.

The actual comparison shows that the performance of the models is about the same. When applied to Askervein Hill, the prediction errors between the calculated and observed winds were from about $8 \%$ to $10 \%$. Plots of wind speed contours derived from model simulations were quite similar, with the exception of the optimizing NOABL model, which exhibited some flow features that did not seen in conformance with the physics of the flow.

For the Altamont Pass simulations, the discrepancy between calculated and observed winds depended upon the number of wind observations available either for model input or for 'post-processing' of the model simulations. Mass-consistent models can accept any number of observations for input, while models that follow J-H theory use only one observation for input to characterize the free-stream flow. However, it is still possible to use additional observations to improve the $\mathrm{J}-\mathrm{H}$ modeling results by post-processing the model simulations so that they conform more closely to the wind observations. The post-processing developed in this report is based on a simple least-squares technique.

When applied to Altamont Pass, all models again exhibited about the same level of skill in predicting the winds. When one station was used for model input, the prediction error of all models was very large, about $25 \%$. When six wind stations were used for either model input or post-processing, this error was reduced to about $9 \%$ for all the models. This improvement illustrates 
that for many modeling situations, the availability of input wind data from several stations is necessary if good results are to be achieved.

A11 the models are well-documented and easy to use. J-H models require more digitized terrain contour data than the mass-consistent type, which is an additional expense that cannot be ignored. All models may be easily operated $\cdot$. on personal computers of the most recent generation. BZ operates very quickly and can calculate the speed at any given point in about a minute. The other models calculate an entire wind field and consequently they require more computer time, on the order of 0.5 to 1 hour. The NOABL model, when operated in the optimizing mode, may take very much longer. 


\section{ACKNOWLEDGMENTS}

The author would like to thank the many people who contributed to the preparation of this report. Ms. Betsy Owczarski provided a fine editorial review. Discussions with Drs. Chris Doran and Larry Wendell pointed the way to many improvements of the report. Mrs. Rosemary Ellis must be commended for her superb typing of the manuscript. Finally, the author would like to thank Drs. Peter Taylor and John Walmsley of the Atmospheric Environment Service of Canada who graciously provided the author with the Askervein Hill wind data set, and Dr. Erik Lundtag Petersen of Ris $\phi$ National Laboratory, Denmark, who provided the "Wind Atlas Analysis and Application Programme" for review at the Pacific Northwest Laboratory. 
$\ddots$

. 


\section{CONTENTS}

SUMMARY ....................... i i i

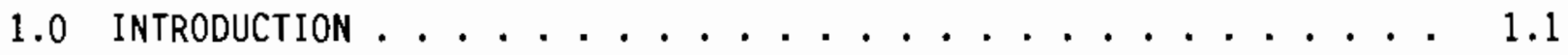

2.0 DESCRIPTION OF THE MODELS . . . . . . . . . . . 2.1

2.1 THE MASS-CONSISTENT MODEL . . . . . . . . . . 2.1

2.2 JACKSON-HUNT THEORY . . . . . . . . . . . . 2.3

3.0 THE WIND DATA SETS . . . . . . . . . . . . . 3.1

3.1 THE ASKERVEIN HILL DATA SET . . . . . . . . . . 3.1

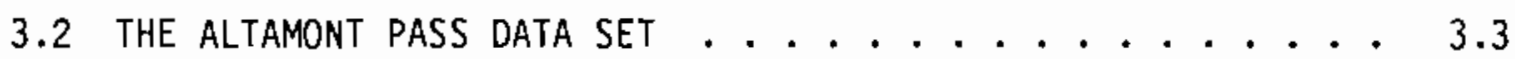

4.0 MODEL COMPARISON . . . . . . . . . . . . . 4.1

4.1 ASKERVEIN HILL MODEL COMPARISONS . . . . . . . . 4.1

4.2 ALTAMONT PASS MODEL COMPARISONS . . . . . . . . . 4.11

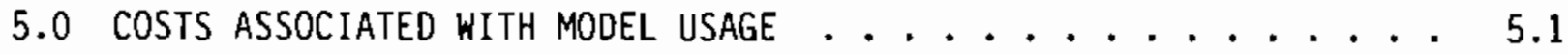

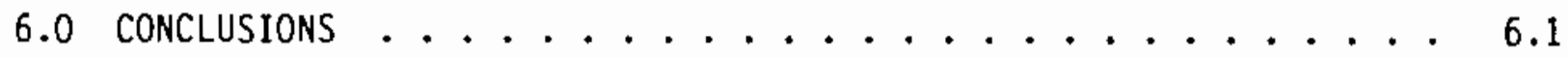

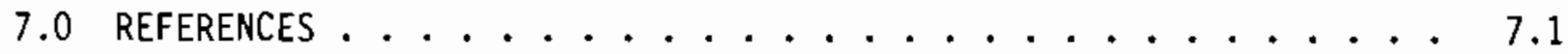


$\cdots$
$\cdots$ 


\section{$\underline{\text { FIGURES }}$}

2.1 The Inner and Outer Layers Employed by Jackson-Hunt Theory . . • 2.4

3.1 Topography of Askervein Hill . . . . . . . . . . . . . . 3.2

3.2 Topography of the Altamont Pass Modeling Domain . . . . . . . 3.5

3.3 The Probability Density Function (PDF) of the Measured Wind Direction for Station 1, Altamont Pass ........... 3.6

4.1 A Comparison of the Observations (Black Dots with Error Bars) and Model-Derived Wind Speeds for the Askervein Hill Case MF03d . .

4.2a Normalized Wind Speed Contours (solid) Derived from the MS3DJH/3R Model Overlaid on Askervein Hill Terrain Contours (dashed) for a Wind Direction of $210^{\circ}$..................

4.2b Normalized Wind Speed Contours (solid) Derived from the NOABL Model Overlaid on Askervein Hill Terrain Contours (dashed) for a

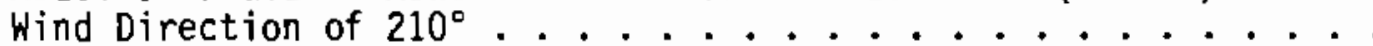

4.2c Normalized Wind Speed Contours (solid) Derived from the Optimizing NOABL Model Overlaid on Askervein Hill Terrain Contours (dashed).

4.3 Model-Derived Normalized Speeds Plotted Versus the Observed Normalized Speeds Obtained from the Askervein Hill Data Set . . 4 4.10

4.4 Model-Derived Speeds ( $\mathrm{m} / \mathrm{s}$ ) Plotted Versus Observed Speeds ( $\mathrm{m} / \mathrm{s}$ ) Obtained from the Altamont Pass Data Set . . . . . . . . .

4.5 NOABL-Derived Speeds (m/s) Plotted Versus Observed Speeds $(\mathrm{m} / \mathrm{s})$, With and Without Post-processing ..............

4.6a Wind Speed Contours (solid) Derived from the Optimizing NOABL Model Overlaid on Altamont Pass Terrain Contours (dashed) . . . .

4.6b Wind Speed Contours (solid) Derived from the MS3DJH/3R Model Overlaid on Altamont Pass Terrain Contours (dashed) 


\section{$\underline{\text { TABLES }}$}

3.1 The Six Mean Flow Cases Used for the Model Comparison . . . . . 3.3

3.2 The 26 Stations and Their Monthly Means for the Altamont Pass Wind Data Set .................. 3.7

4.1 Model Grid Parameters - Askervein Hill . . . . . . . . . . 4.2

4.2 RMSEs of Normalized Speeds for Model Simulations of the Flow Over Askervein $\mathrm{Hill}$. . . . . . . . . . . . . . . . 4.3

4.3 Model Grid Parameters - Altamont Pass . . . . . . . . . . . 4.12

4.4 RMSEs ( $\mathrm{m} / \mathrm{s}$ ) and Prediction Errors (\%) for the Altamont Pass Modeling Simulations... . . . . . . . . . . . . . . 4.14

5.1 Relative Computer Time for Model Operation . . . . . . . . 5.3 


\subsection{INTRODUCTION}

Wind farm developments are often located in areas of complex terrain. over such terrain, it is not unusual for the wind speed to vary significantly over short distances. Clearly it would be desirable to know, before a wind farm is constructed, the pattern of the wind speeds over the area of interest so that turbines may be located only in places where the wind is sufficiently strong to make the turbines economically viable. The siting of turbines over an area the size of a wind farm has been termed 'micrositing' by those working in the wind energy field, and because profitable micrositing depends upon some knowledge of the wind flow over a proposed wind farm, a demand has been generated for methods of estimating the flow. One such method is through the use of numerical wind flow models.

These models simulate the flow by solving equations that represent the physics of the flow. Some models use very simple equations that embody only a minimal amount of physics, while others do just the opposite, and in fact, the models can be classified by how much physics is contained in the model equations. The most complicated models are the time-dependent primitive equation models whose formulation attempts to include most of the physics of the flow. Because of the great complexity of these models, they may require large amounts of input data and computer time and are often very difficult to use. Furthermore, it is uncertain whether the large effort required to run these models is rewarded with significantly more accurate wind simulations than. those obtained from simpler models (Pennell 1982). At this time, these factors have caused a reluctance to accept primitive equation models for micrositing purposes, and this task has fallen to the simpler models.

A number of simplified physics models have been proposed as micrositing tools in complex terrain, and two categories of these models witl be investigated in this paper. In the first category are the so-called mass-consistent models, one of which is described by Sherman (1978). The operating principle of these models is quite simple. Wind observations made over the modeling domain are used by the model to construct an initial guess of the wind field. Then an adjustment is applied to this initial guess so that 1) the final, calculated wind field conserves mass and 2) the velocity vectors at the terrain 
surface are parallel to the surface. An important feature of the adjustment is that it is just the minimum amount required to conserve mass. Thus, the calculated field retains some similarity to the initial field and the wind observations upon which it was based. Because the goal of these models is to calculate a field that conserves mass, they are termed 'mass-consistent' models. (Although almost all other models likewise conserve mass, it is commonty understood that the label 'mass-consistent' specifically refers to the model described above.)

A second category of model is based on the theory of Jackson and Hunt (1975). (Jackson and Hunt will be indicated by $\mathrm{J}-\mathrm{H}$ from henceforth.) $\mathrm{J}-\mathrm{H}$ models differ dramatically from the mass-consistent models described above: instead of being content with mass conservation alone, $\mathrm{J}-\mathrm{H}$ models attempt to solve a set of equations that include momentum conservation as well as mass conservation. The momentum equations are those that represent incompressible, time-independent, neutrally stratified turbulent flow. Because an exact solution of these equations is very difficult to find, mathematical and physical approximations must be made to have any hope of calculating even an approximate solution. The most important of these approximations are the linearization of the momentum equations and the use of a simple mixing length scheme as a turbulence closure.

Because of the greater physical verisimilitude of the $\mathrm{J}-\mathrm{H}$ approach, it would seem that the mass-consistent models would be no match for $3-H$ models. However, the approximations inherent to the $\mathrm{J}-\mathrm{H}$ theory may induce significant errors into wind field simulations, particularly when the model is applied to very complex terrain with relatively steep terrain slopes. Therefore, it is not possible to determine a priori, just by an examination of the physics and mathematics of the models alone, which type would exhibit superior performance, and a direct comparison of the models with actual wind data is necessary. Such a comparison is the main goal of this report.

Three specific models are considered in this report: two that are descendants of $\mathrm{J}-\mathrm{H}$ theory, and one of the mass-consistent genre. The $\mathrm{J}-\mathrm{H}$ type models are: 1) MS3DJH/3R developed at the Atmospheric Environment Service of Canada and described by Walmsley et al. (1986), and 2) BZ (Troen and Petersen 1989), part of the WAsP wind analysis package developed by Denmark's Ris National 
Laboratory (Troen et al. 1988). Although both models have been derived from $\mathrm{J}-\mathrm{H}$ theory, there are very important differences between the two as will be described in Section 2. The mass-consistent model considered here is the NOABL model described by Traci et a1. (1978). This model was then refined by Barnard et al. (1987) so that the model could be operated in an 'optimizing' . mode. When exercised in this mode, the model is automatically tuned to any wind observations available over the modeled area. In this paper, use of the model in the normal and optimizing modes will be examined.

Model verification studies have been performed in the past that have compared wind simulations derived from only one model to wind observations. Waimsley and Salmon (1984) compared wind data from the 1983 Askervein Hill measurement program (Taylor and Teunissen 1987) to modeled winds calculated from MS3DJH/3 (an earlier version of $M S 3 D J H / 3 R$ ). They found that the agreement between model-derived speeds and the observations was excellent, except on the lee side of the hill where the model overestimated the actual speed. Similarly, very favorable comparisons between observations and wind simulations were reported by Barnard et a1. (1987), who applied the NOABL model, operated in the optimizing mode, to complex terrain in the Altamont Pass area of California.

The ability of BZ, NOABL, and TMODEL (a modified version of NOABL) to simulate the winds at 15 locations on the southern part of the island of Sardinia was studied by Sempreviva et al. (1986). In that paper, a quantitative measure of the error between the calculated and observed winds was not provided. However, scatterplots of observed versus calculated winds al low one to conclude that the performance of $B Z$ was better than the other two models.

More recent studies have examined the skill of more than just one model to predict speeds at wind observation sites. Lalas et al. (1988), working with three mode ls, MS3DJH/3R, BZ, and a slightly modified version of NOABL (termed $N O A B L^{*}$ ), compared modeled and observed winds at two sites on the rough terrain of the Greek island of Limnos, and observed that the performance of all three models was about the same, although BZ was slightly more accurate than the other two. 
Barton and Hunter (1988) investigated the performance of four "wind resource prediction techniques" in predicting winds at a single test site, located about $28 \mathrm{~km}$ distant from a reference site. Wind data collected at the reference site served as input for the techniques, two of which were the models BZ and MS3DJH/3R. (Unfortunately, the authors were not able to operate. MS3DJH/3R because of computer difficulties, and although the model was discussed in the paper, its performance was not evaluated). BZ was operated within the WASP wind analysis framework. The difference between the mean speed at the test site $(7.3 \mathrm{~m} / \mathrm{s})$ and the speed calculated by WAsP $(5.8 \mathrm{~m} / \mathrm{s})$ was relatively large $(1.5 \mathrm{~m} / \mathrm{s})$. The best match between calculated and observed winds occurred in a direction sector centered on $210^{\circ}$, a direction at which the reference site is roughly upwind of the test site.

Walmsley et al. (1989) compared model calculated winds from four models to wind data from the Blashaval experiment. The models examined were three $\mathrm{J}-\mathrm{H}$ type models (Mason-King Model D, MS3DJH/3R, and BZ), and a mass-consistent model (NOABL ${ }^{\star}$ ). In this comparison, the match between the observed and calculated speeds at the summit of Blashaval Hill was reasonably good for all four models. At an observation site near the base of the hill, NOABL* underpredicted the actual winds, while the other models provided speeds close to the observed values. Vertical profiles of the calculated speeds were also examined.

For most of the studies summarized above, either wind data from only a few stations were available for comparison with several models, or if more observations sites were present, as in the case of Askervein Hill (Walmsley and Salmon 1984), then only a single model was compared with these data. The present investigation differs from these other studies in an important way: several models will be compared simultaneously using two wind data sets that contain many wind observation sites. The first data set is from the 1983 Askervein Hill experiment, and it consists of roughly 40 observations taken over an isolated hill. The second set consists of about 30 observations and is from Altamont Pass, California, where the terrain is much more varied than Askervein Hill. Moreover, because Altamont Pass has become an area of considerable wind energy development, application of models to this area is a true test of their practicality for micrositing purposes. 


\subsection{DESCRIPTION OF THE MODELS}

The intent of this section is to provide the reader with a brief and highly simplified description of the models. A complete description of the theoretical basis of the models is beyond the scope of this report, and those readers who desire further information may consult the references.

\subsection{THE MASS-CONSISTENT MODEL}

The theory behind the mass-consistent model has been described by Sherman (1978). It is perhaps best to think of this model as an intelligent interpolation/extrapolation scheme that begins with knowledge of the wind at specific points - the wind observations. These observations are used as a basis of estimating the wind at every point of a three-dimensional modeling domain that sits atop the terrain over which knowledge of the winds is desired. The model performs this task using two distinct steps.

The first of these is to construct an initial guess of the wind field at every point in the modeling domain. The observations form the starting point from which the initial guess is made but, because the observations are point measurements, a method must be devised of extrapolating the wind data from these points throughout the entire domain. There are many ways of doing this; we briefly describe one. First, vertical profiles of the horizontal winds are established at each observation site. These profiles are based either on a power law or logarithmic extrapolation of the wind observation up to a fixed height. Above this height the speed is taken to be constant. Once these vertical profiles have been constructed, horizontal interpolation is required to fill in the initial guess at all remaining points between the profiles. This horizontal interpolation is performed using the comnon inverse square weighting. The initial guess of the vertical velocity is set to zero at all points except at the terrain surface, where it is calculated so that the initial guess of the wind vector is parallel to the surface.

The above procedure provides an initial guess of the wind throughout the modeling domain. The mass-consistent model is not content to stop with such an estimate, however. It then attempts to improve upon the initial guess by 
a mass-consistent adjustment that comprises the model's second and final step: the initial guess is adjusted the minimum amount so that the final, calculated velocity components, $u, v$, and $w$, satisfy the equation of mass conservation:

$$
\frac{\partial u}{\partial x}+\frac{\partial v}{\partial y}+\frac{\partial w}{\partial z}=0 \quad .
$$

Additionally, a boundary condition imposed at the surface of the modeling domain requires that the calculated wind be parallel to the surface. The actual adjustment procedure - a minimization - is performed using techniques from the calculus of variations.

Another feature of the mass-consistent adjustment is that preference may be given to the adjustment in either the horizontal or vertical direction. The parameter that governs the relative adjustment in each direction is given the symbol $\tau$ and it acts as an empirical stability parameter for the model. For this report, $\tau$ is defined as $\log _{10}\left(a_{1} / \alpha_{2}\right)^{2}$, where $a_{1}$ and $\alpha_{2}$ are the (usual) weighting factors for the horizontal and vertical directions, respectively (Sherman 1978). $\tau$ must be specified by the user before operating the model, although there is a way of circumventing this requirement as will be described below. Values of $\tau$ less than zero encourage more adjustment in the horizontal direction than the vertical direction and simulate a stable flow, in which an air parcel is more likely to go around a terrain obstacle than over it. In a similar way, values of $\tau$ greater than, or equal to zero, simulate flow that is unstable or neutral, respectively.

Flow simulations may be quite sensitive to the value of $\tau$. Because it is often not possible to find appropriate values for this parameter, confidence in the calculated winds derived from mass-consistent models has been low. This difficulty was attacked by Barnard et al. (1987) in a recent improvement of the mass-consistent model in which optimum values of $\tau$ are determined by adjusting $\tau$ until the difference between the model-derived and observed speeds is minimized. This 'optimizing' procedure relies on the availability of a number of wind observations over the area of interest; at least three stations are required. In this paper, both data sets contain enough observations so that the optimizing mode of the mass-consistent model may be tested. 
Over the past decade, the mass-consistent model has been modified by various research groups, each producing their own refined version of the model. This study will work with one of these versions, the NOABL mass-consistent model developed by Traci et al. (1978). This model will be operated both with and without the optimization feature described above.

\subsection{JACKSON-HUNT THEORY}

It is fair to say that models which follow the theory of Jackson and Hunt (1975) are radically different from mass-consistent models. Perhaps the major difference between the two is the role of momentum conservation. Like mass-consistent models, J-H models conserve mass but, in addition, J-H models attempt to solve the momentum (Navier-Stokes) equations, while mass-consistent models completely ignore them. Because of the extreme difficulties associated with finding exact solutions to the complete momentum equations for flows in complex terrain, J-H models seek only an approximate solution, which is achieved through the use of two approximations. The first of these is a simplification of the physics of the flow, which is the use of the well-known mixing length closure for the turbulent (Reynolds) stresses. The second approximation is mathematical: the momentum equations are linearized, and the linearized equations are solved using perturbation techniques.

The perturbation technique first requires a known solution to the momentum equations - with a mixing length turbulence closure - for flow over flat terrain. This is the well-known logarithmic profile. Then, a low hill of limited horizontal and vertical extent is introduced into this flow, and small perturbations induced by the hill are calculated. These perturbations are then added to the (vertically displaced) logarithmic profile to achieve the final, calculated solution. The perturbations are required to vanish at distances far away from the hill at the boundary of the modeling domain, where the flow is assumed to be unaffected by the hill and identical to the logarithmic profile. The requirement that the winds are unchanged at the boundary of the modeled area means that, in effect, the terrain is immersed in a uniform freestream flow. This assumption of an uniform free-stream flow has important consequences for the application of $\mathrm{J}-\mathrm{H}$ models. 
Outer Layer - The perturbed flow is inviscid and irrotational.

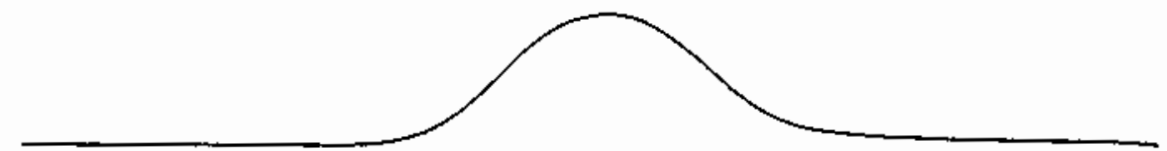

Inner Layer - The perturbed flow involves a balance between inertial, pressure, and turbulent stress forces. The pressure is obtained from the outer layer solution.

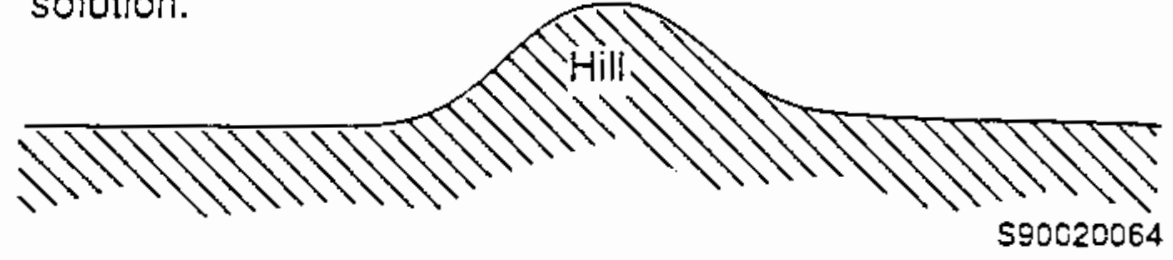

FIGURE 2.1. The Inner and Outer Layers Employed by Jackson-Hunt Theory

The calculation of the perturbed quantities is mathematically complicated. The calculation is simplified, however, by dividing the atmosphere into two layers, as shown in Figure 2.1. In the upper layer, the influence of the hill on the flow is diminished, and $\mathrm{J}-\mathrm{H}$ theory argues that in this 'outer layer' the perturbed turbulent stresses are negligible. Therefore, the perturbed flow in outer layer, which is irrotational, may also be regarded as inviscid, and further simplification of the linearized momentum equations is possible. For example, the equation governing the (first-order) perturbed pressure field is Laplace's equation, with simple boundary conditions, to which a solution is easily found.

The perturbed pressure field in the outer flow supplies the pressure gradient force in the inner layer that drives the flow in this layer. Consequently, in the inner layer the pressure field is a given and need not be calculated. This simplification is offset, however, because the flow in this 
layer is greatly influenced by the earth's surface which forms its lower boundary, and the perturbation turbulent stresses induced by the boundary cannot be neglected. The inclusion of the turbulent stresses in the inner flow equations makes these equations more complicated than those of the outer flow, because the inner equations involve the balance of not only the inertial and pressure gradient forces, but the turbulent stress force as well. Despite this increase in complexity, analytical solution of the inner flow equations is still possible using transform techniques.

Velocities calculated in both the inner and outer layers are not independent of one another and must be linked together; this linking is done through a 'matching condition' at the interface between the layers. Specifically, this condition is that the vertical velocities must be identical. Once one determines the velocities in the inner and outer layers and the matching is performed, the calculation is complete.

After its original development, $\mathrm{J}-\mathrm{H}$ theory was extended to threedimensions by Mason and Sykes (1979). Furthermore, numerous improvements of the 3-dimensional version were made as part of the development of the MS3DJH/3R model, one of the models examined in this paper. These improvements include wave-number dependent scaling (Taylor et al. 1983) and the incorporation of surface-roughness effects (Walmsley et al. 1986).

Like MS3DJH/3R, the BZ model has evolved from the J-H theory, but it contains some very significant differences from MS3DJH/3R that are worthy of note. Perhaps the greatest difference is the coordinate system in which the model equations are solved. MS3DJH/3R uses a standard Cartesian coordinate systern and solves for the wind speed at each point in the modeling domain, which is a rectangular box. In marked contrast, BZ employs a polar coordinate system, and the wind speed is calculated only at the origin of this system. Moreover, the polar grid is a 'zooming grid' where the grid point separation is small near the grid's center, and increases as the radial distance increases. The advantage of the zooming polar grid is that it allows a fine spatial resolution of computed quantities and terrain in the vicinity of the origin - the very location where an estimate of the wind is sought. 
'

$\ddots$ , 


\subsection{THE WIND DATA SETS}

Two wind data sets, Askervein $\mathrm{Hill}$ and Altamont Pass, were selected for this model comparison study. The Askervein Hill set is from an isolated hill located on South Uist, an island in the Outer Hebrides chain of Scotland, and the Altamont Pass data are from the Altamont Pass area near San Francisco, California, in the United States. These two sets are particularly well suited for a model comparison study because they contain wind observations of a relatively fine spatial and temporal resolution. Additionally, the large difference in the terrain between the two locations permits a more comprehensive comparison between the models.

\subsection{THE ASKERVEIN HILL DATA SET}

The Askervein $\mathrm{Hill}$ wind measurements were taken for the purpose of characterizing the wind and turbulence properties in the boundary layer flow over a low hill that would typify the location of a wind turbine site. The measurement program consisted of two field operations, one during September and October of 1982 and the other during the same months of 1983. Detailed reports describing each year's activities are available (Taylor and Teunissen 1983, Taylor and Teunissen 1985), and an overview of the program, including a brief description of the hill itself, the instrumentation deployed, and a surmary of data collected, has been given by Taylor and Teunissen (1987). In this report, only data from the 1983 experiment will be used.

The topography of the hill is shown in Figure 3.1, where terrain contours at $10-\mathrm{m}$ intervals have been plotted. The high point of the hill (located close to the letter $B$ in the figure) is about $116 \mathrm{~m}$ above the surrounding terrain, which is essentially flat and about $10 \mathrm{~m}$ above sea level. Maximum terrain slopes are moderate, about $20 \%$, so the linearization error of $\mathrm{J}-\mathrm{H}$ type models should not be very large. The hill is covered by grass, heather, and low scrub, and the surface roughness, $z_{0}$, is fairly uniform over the hill and surroundings. A representative value of $z_{0}$ is $0.03 \mathrm{~m}$, and models that require surface roughness as part of their input will use this value. 


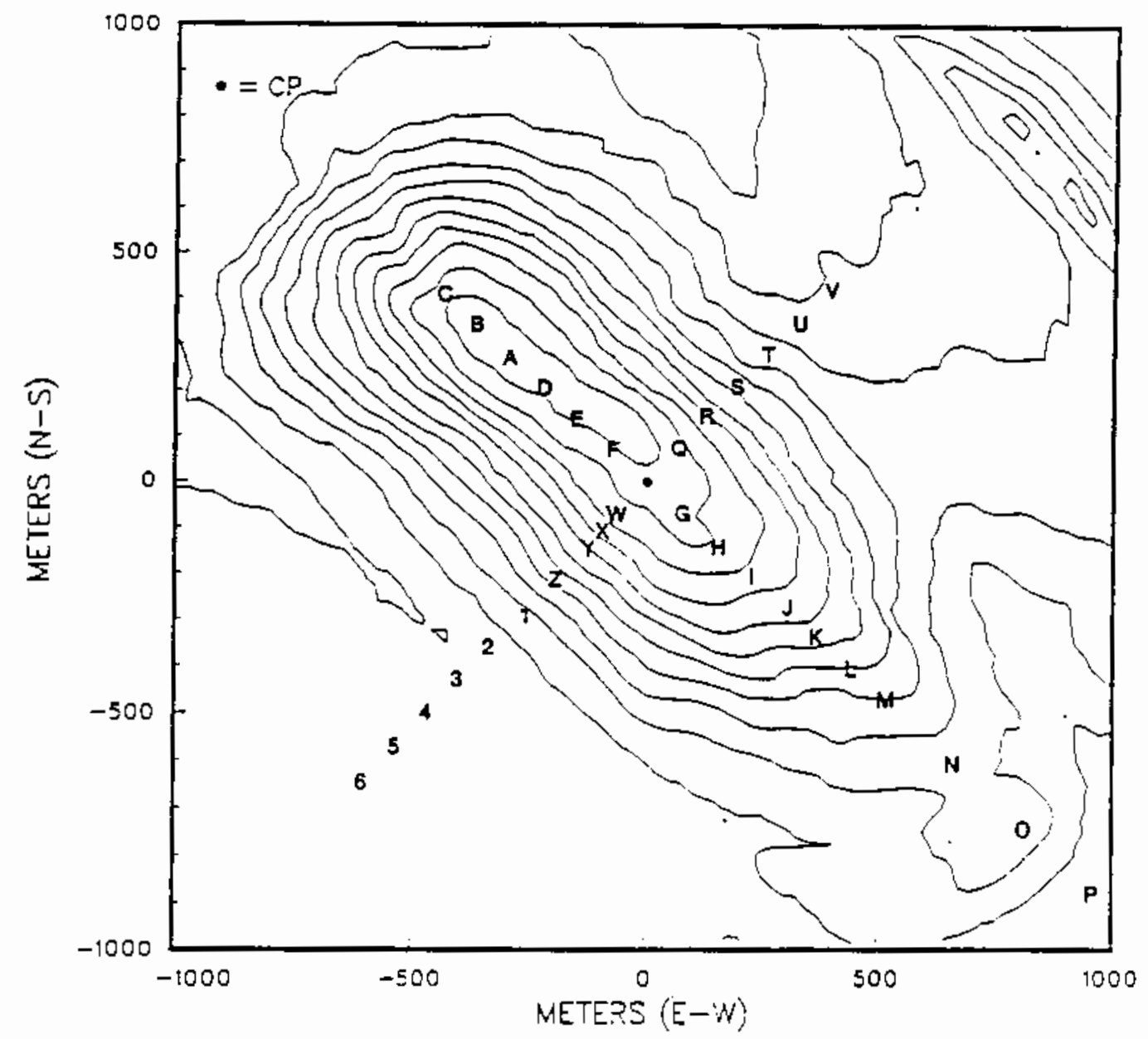

FIGURE 3.1. Topography of Askervein Hill. The terrain contour interval is $10 \mathrm{~m}$. The alphanumeric characters identify the locations of the wind observation sites.

From all the data collected during the 1983 experiment, a subset was selected for the model comparison. Wind data in this subset are part of the 'mean flow' (MF) runs described in the Askervein Hill data reports. The mean flow data consist of wind speeds measured at the 10-m level. (Although the height of the measurements was changed to $3 \mathrm{~m}$ near the conclusion of the 1983 experiment, none of these data are used here.) The positions of the 32-MF anemometers are indicated by the alphanumeric characters in Figure 3.1, where it is seen that the anemometers were deployed in two lines oriented approximately NE-SW and SE-NW. In addition, wind speed and direction data were collected at a reference site located about $3 \mathrm{~km} \mathrm{SSW}$ of the hill. The purpose of that site was to measure the undisturbed wind speed at a place outside of the hill's influence. 
Data were collected and averaged over a 10-min period. Data taken over an unbroken period of time when the undisturbed wind speed and direction remained relatively constant were grouped together to form 'MF runs'. From the 1983 experiment 46 MF runs were formed, and of these 46 runs, six cases were selected for comparison with the model simulations. These cases are shown in Table 3.1. For all cases there is no overlap in both undisturbed wind speed and direction as measured at the reference site, although two of the six (MFO2a and MFO3d) possess the same direction (but have different speeds). Model comparisons will be made to each individual case and to an average case formed by averaging the speeds at each of the 32 anemometers over the six MF cases.

TABLE 3.1. The Six Mean Flow Cases Used for the Model Comparison. The direction and speed indicated below were measured at the reference site. $N$ is the number of stations from which wind data were obtained over the duration of the case.

\begin{tabular}{|c|c|c|c|c|}
\hline Case & $\underline{N}$ & $\begin{array}{l}\text { Mean Wind } \\
\text { Speed }(\mathrm{m} / \mathrm{s})\end{array}$ & $\begin{array}{c}\text { Mean } \\
\text { Direction }\left({ }^{\circ}\right)\end{array}$ & $\begin{array}{l}\text { Duration } \\
\text { (hours) }\end{array}$ \\
\hline MF28d & 14 & 6.0 & 105 & 14.0 \\
\hline MF01a & 28 & 13.0 & 140 & 3.0 \\
\hline MF02a & 25 & 6.8 & 210 & 5.0 \\
\hline MF02c & 30 & 11.0 & 165 & 4.0 \\
\hline MF03d & 28 & 8.9 & 210 & 3.0 \\
\hline MF05c & 29 & 12.0 & 268 & 1.0 \\
\hline
\end{tabular}

\subsection{THE ALTAMONT PASS DATA SET}

The Altamont Pass region of California has been one of the world's most active areas of wind farm development. The pass is located roughly $70 \mathrm{~km}$ due east of San Francisco, California. The terrain is very complicated, consisting of many hills and some steep terrain slopes. This terrain complexity contrasts sharply with Askervein Hill, which is an isolated hill of moderate slope. However, both areas are treeless and of uniform surface roughness, and the roughness length selected for Askervein Hill, $z_{0}=0.03 \mathrm{~m}$, seems appropriate for Altamont Pass as well. 
The wind data set consists of measurements taken at about 58 sites covering an area of about $10 \mathrm{~km}^{2}$. The measurements were taken to evaluate the windiness over this area before the installation of a commercial wind farm. The winds were observed at a height of $13.7 \mathrm{~m}$ and reported as hourly averages. For this study only 26 of the 58 sites were used. This reduction in the number of sites was necessary for two reasons, the first of which is the desire to avoid digitizing a large area of terrain, a task which can be extremely time consuming and tedious if done conscientiously! ( $\mathrm{J}-\mathrm{H}$ models require digitized terrain not only over the area to be modeled, but also along the borders of this area, so if one wished to model all $10 \mathrm{~km}^{2}$, a total of about $20 \mathrm{~km}^{2}$ of digitized terrain would be necessary.) The second reason concerns the usuat trade-off between terrain resolution and number of model grid points. Because it was desirable to retain a relatively fine terrain resolution while simultaneousiy keeping the number of model grid points to a minimum, only an area smaller than the full $10 \mathrm{~km}^{2}$ was modeled.

The terrain contours, at 10-m intervals, and the location of the 26 stations as indicated by the alphanumeric characters are shown in Figure 3.2. Comparing this figure with Figure 3.1, whose contour interval is the same, vividly reveals the marked difference in terrain complexity between Askervein Hill and Altamont Pass. Wind speed data collected at these sites during the month of August 1985 and reported as hourly averages compose the data used for the model comparison. Within the modeled area, wind direction measurements were made at station 1, and the probability density function (PDF) of these measurements is shown in Figure 3.3. Clearly, the wind speed is very unidirectional during most of the month, and the most frequent direction is $233^{\circ}$.

The wind data for the month of August consists of 744 hourly averaged values. Most models cannot be run for each of these cases because of prohibitive computer and labor costs. For this data, however, a drastic simplification is possible because for each hourly case, the wind speeds are extremely well correlated with one another, and for a given hour, the ratio of speeds between any two sites is usually very close to the ratio of the monthly means at these sites. This assertion was verified by performing a principal components analysis (PCA) of the data in which it was shown that the monthly means explained more than $99 \%$ of the total variance. (For brevity, 


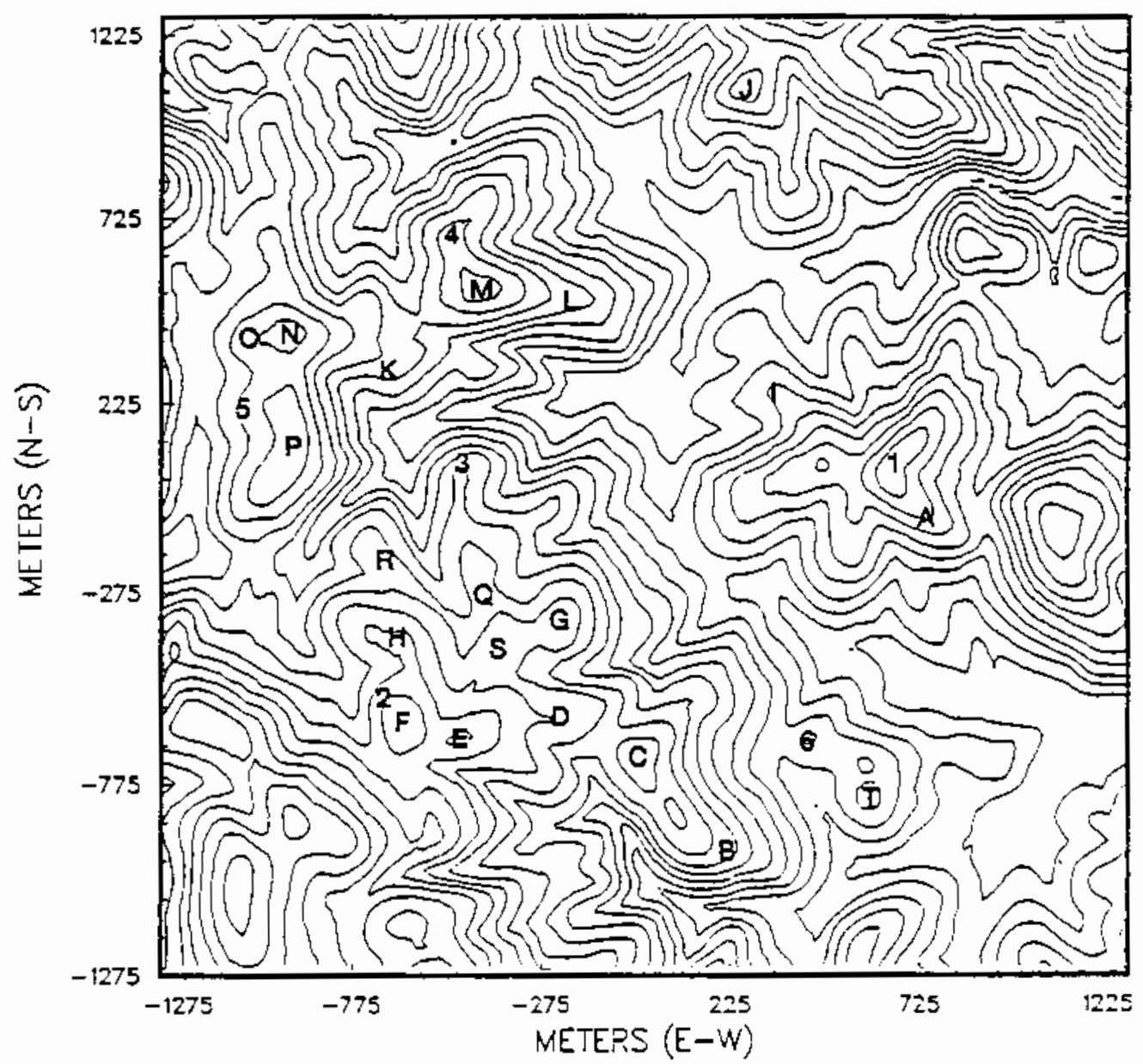

FIGURE 3.2. Topography of the Altamont Pass Modeling Domain. The terrain contour interval is $10 \mathrm{~m}$. The alphanumeric characters indicate the locations of the wind observation sites.

we omit the details of the PCA analysis.) Because of this fortuitous but not unexpected circumstance, each model needed only be run once to predict the monthly means.

In spite of the PCA analysis, one may still question the use of monthly means for model input and evaluation; however, further evidence that this procedure is valid, at least for the Altamont Pass area, has been provided by Barnard and Germain (1988). In this study, mean monthly speeds at various Altamont Pass sites were derived from the optimizing NOABL model. Input to the model was either of the following: (1) 30 sets of observations selected to represent the wind speed patterns during the month, in which case the model was operated 30 times and the results averaged, or (2) mean monthly speeds, 
in which case the model was operated only once. The mean speeds derived from both these strategies were nearly identical suggesting that the use of mean speeds for model input is a reasonable procedure.

Table 3.2 lists the stations and their mean monthly speeds. It is important to note that the wind speed increases as one moves from the west towards the east in the modeling domain. This increase in speed is a manifestation of a general downslope flow acceleration that occurs at Altamont Pass. This acceleration causes difficulties for J-H models, because in order for them to work well, they require that the unperturbed, free-stream flow be uniform over the modeling domain.

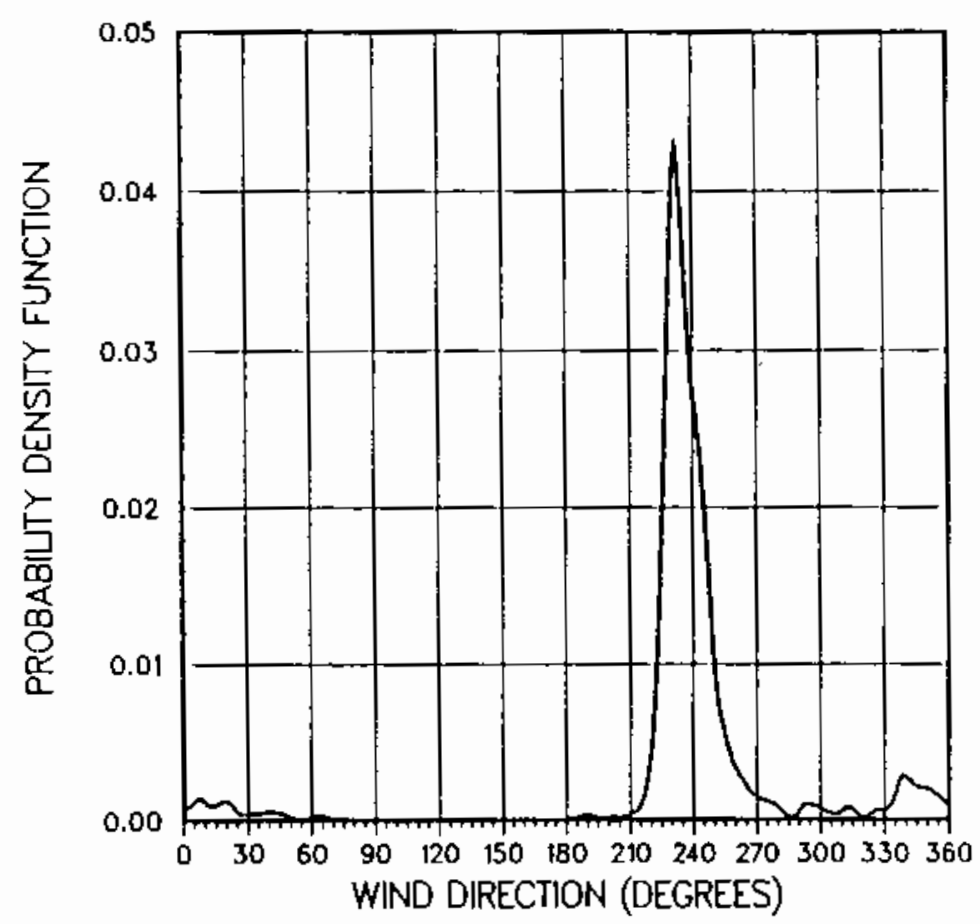

FIGURE 3.3. The Probability Density Function (PDF) of the Measured Wind Direction for Station 1, Altamont Pass. The PDF was derived from the 744 hourly observations taken during August 1985. 
IABLE 3.2. The 26 Stations and Their Monthly Means for the Altamont Pass Wind Data Set

\begin{tabular}{|c|c|c|c|}
\hline Station & $\begin{array}{l}\text { Mean Wind } \\
\text { Speed }(\mathrm{m} / \mathrm{s})\end{array}$ & Station & $\begin{array}{l}\text { Mean Wind } \\
\text { Speed }(\mathrm{m} / \mathrm{s})\end{array}$ \\
\hline 1 & 13.0 & H & 10.7 \\
\hline 2 & 9.5 & I & 10.8 \\
\hline 3 & 11.1 & $\mathrm{~J}$ & 10.7 \\
\hline 4 & 10.6 & K & 9.1 \\
\hline 5 & B. 2 & L & 11.2 \\
\hline 6 & 11.7 & $M$ & 11.7 \\
\hline A & 12.8 & N & 10.3 \\
\hline B & 12.2 & 0 & 8.7 \\
\hline C & 12.5 & P & 10.4 \\
\hline D & 10.9 & $Q$ & 10.4 \\
\hline$E$ & 10.3 & $\mathrm{R}$ & 10.5 \\
\hline$F$ & 10.5 & $S$ & 10.8 \\
\hline G & 12.0 & $T$ & 11.9 \\
\hline
\end{tabular}




\subsection{MODEL COMPARISON}

An evaluation of the models is performed in this section by comparing model simulations of the wind flow to actual wind data. A model's skill in predicting winds is quantitatively measured by a figure of merit, which we shall choose to be the root mean square error (RMSE), defined as

$$
\text { RMSE }=\left[\frac{\sum_{i=1}^{N}\left(s_{c}^{i}-s_{0}^{i}\right)^{2}}{N}\right]^{1 / 2}
$$

where $s_{0}^{i}$ is the observed wind speed at site $i, s_{c}^{i}$ is the calculated speed at the same site, and $N$ is the number of stations over which the comparison is performed. Because it is often useful to represent the error by a number whose magnitude does not depend on the measurement units of the wind speed (i.e., a non-dimensional number), we also define a 'prediction error', which is the RMSE divided by the mean of the observed speeds. This error is multiplied by 100 and expressed as a percentage.

\subsection{ASKERVEIN HILL MODEL COMPARISONS}

All three models were applied to Askervein Hill. For these model runs, the model grid parameters (i.e., the number of grid points and the distance between them) are listed in Table 4.1 for NOABL and MS3DJH/3R. The origin $(0,0)$ of the Cartesian grid of NOABL and MS3DJH/3R is the center point of Askervein Hill, as indicated by the black dot labelled ' $C P$ ' in Figure 3.1.

BZ automatically sets up a zooming grid and the specification of grid parameters is not necessary. However, it is still obligatory to furnish the model with terrain contours from which the zooming grid is constructed. The number of contours and terrain elevations that can be accepted by $B Z$ are limited by model storage space and a terrain contour interval must be specified; this is also given in Table 4.1. The origin of BZ's zooming grid is the location where the speed is to be calculated, and to calculate the speed at every observation site in a modeling domain, the model must be operated 
TABLE 4.1. Model Grid Parameters - Askervein Hill

$\begin{array}{ccc}\text { Model } & \text { Grid Spacing (m) } & \text { Grid Size } \\ & 25 & 256 \times 256 \\ \text { NOABL } & 50 & 41 \times 41\end{array}$

$\frac{\text { Model }}{B Z} \quad \frac{\begin{array}{c}\text { Terrain Contour } \\ \text { Interval (m) }\end{array}}{6}$

for one site, then the origin much be relocated, and the model operated again. This procedure is repeated until the simulated speeds at all the observation sites have been determined.

The models were run for all six data cases listed in Table 3.1. Before the simulations were compared with the data, the observations for each case were normalized by dividing all the observed speeds by the speed at the reference site. These nomalized speeds are termed 'normalized observed speeds', to distinguish them from the 'normalized simulated speeds', which were determined by multiplying all the simulated speeds by a factor chosen such that the simulated speed at site $C P$ was equal to the observed normalized speed at this site. Several anemometers were clustered together at this site, and the observed nomalized speed here was taken to be an average of the observed normalized speeds from two of these anemometers. (For those familiar with the Askervein $\mathrm{Hill}$ data set, these two anemometers were BSE40 and BSE4OH.)

The NOABL model was operated in both the normal and optimizing modes. When operated in the normal mode, the stability parameter, $\tau$, must be specified by the user, and it was set equal to 0 , corresponding to neutral stability. When operated in the optimizing mode, four stations were selected as tuning sites to which the model was automatically tuned; these stations were stations $B, C P$ (the average of BSE4O and BSE4OH), $U$, and 2. However, for two of the six cases, MF03d and MFO5C, wind data at station $U$ was missing, and for these two cases the model was only tuned to the three remaining stations, B, CP, and 2. 
TABLE 4.2. RMSEs of Normalized Speeds for Model Simulations of the Flow Over Askervein Hill. The prediction error of the average of the six cases is listed at the bottom of the table.

\begin{tabular}{|c|c|c|c|c|}
\hline \multirow[b]{2}{*}{ Case } & \multicolumn{4}{|c|}{ Model } \\
\hline & MS3DJH/3R & $\mathrm{BZ}$ & NOABL & $\begin{array}{l}\text { Optimizing } \\
\text { NOABL (a) }\end{array}$ \\
\hline MF28d & 0.101 & 0.096 & 0.115 & 0.069 \\
\hline MFOIa & 0.050 & 0.052 & 0.053 & 0.068 \\
\hline MFO2a & 0.134 & 0.136 & 0.163 & 0.180 \\
\hline MF02C & 0.105 & 0.091 & 0.103 & 0.086 \\
\hline MF03d & 0.124 & 0.136 & 0.141 & 0.232 \\
\hline$M F 05 C$ & 0.115 & 0.120 & 0.130 & 0.166 \\
\hline \multirow[t]{2}{*}{$\begin{array}{l}\text { Average of } \\
6 \text { cases }\end{array}$} & 0.100 & 0.095 & 0.108 & 0.121 \\
\hline & \multicolumn{4}{|c|}{ Prediction Error (\%) } \\
\hline $\begin{array}{l}\text { Average of } \\
6 \text { cases }\end{array}$ & 8.4 & 7.9 & 9.1 & 10.1 \\
\hline
\end{tabular}

(a) For the optimizing NOABL model, the tuning stations were excluded from the calculation of the RMSE.

For each of the six cases, the performance of the models as indicated by the RMSE is listed in Table 4.2. The RMSEs were determined using the normalized speeds mentioned above. Looking at this table, the reader may observe that on a case-by-case basis, the performance of the models is nearly identical, except that optimization makes the NOABL results very much worse in some cases, notably case MF03d, or much better, as in case MF28d.

To illustrate the performance of the models for a single case, simulated and observed normalized speeds have been plotted in Figure 4.1 for case MF03d. This figure segregates the observed and simulated winds into two parts. The top part consists of the simulated and measured winds along the line of anemometers that lies along the ridge of the hill and is oriented SE to NH, while the bottom part plots these quantities along the line of anemoneters that is perpendicular to the ridge and is oriented $\mathrm{SW}$ to $\mathrm{NE}$; both these lines are easily discerned in Figure 3.1. For this particular case, the wind direction 

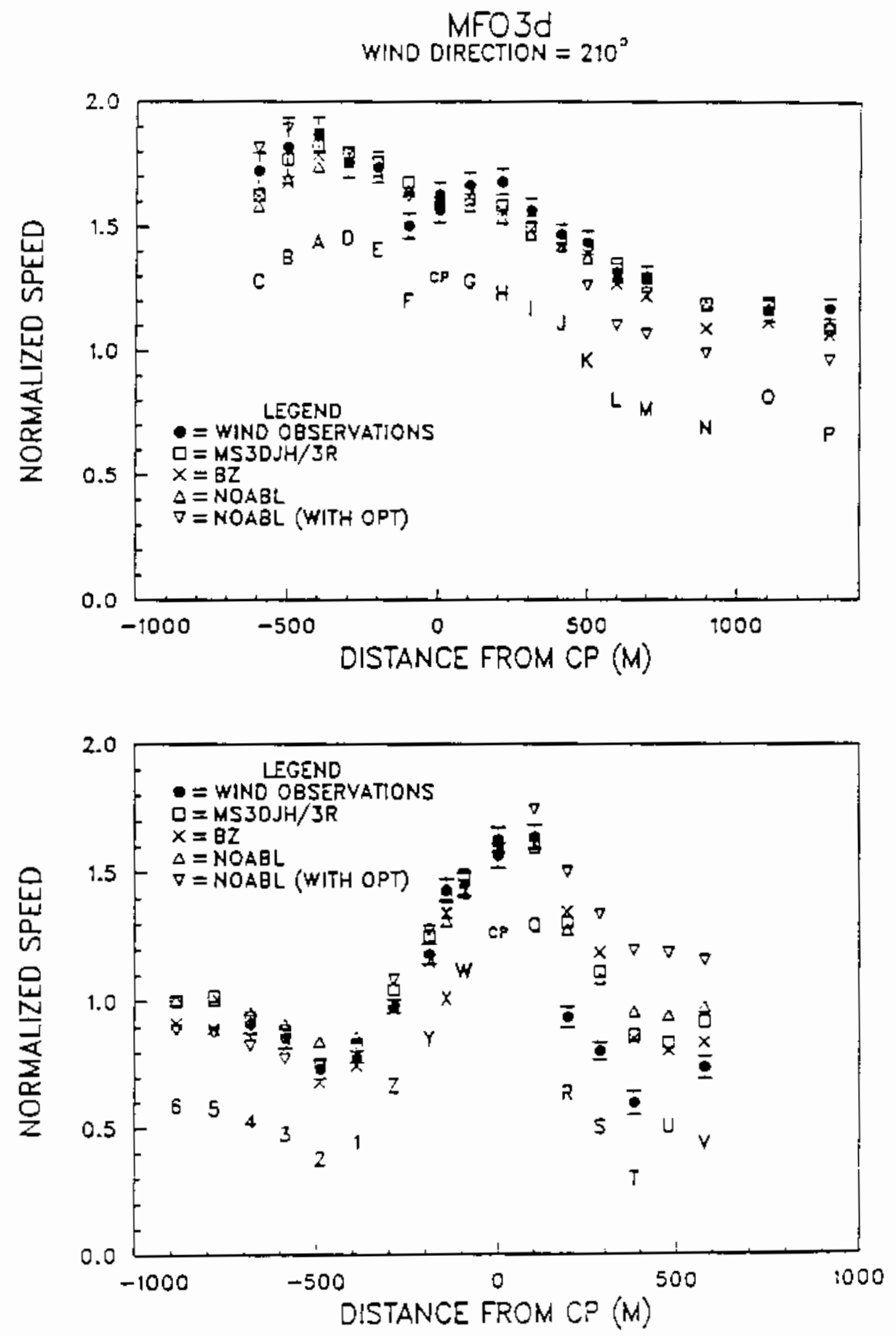

FIGURE 4.1. A Comparison of the Observations (Black Dots with Error Bars) and Model-Derived Wind Speeds for the Askervein Hill Case MFO3d. The station identifiers are plotted below the nomalized speeds. 
at the reference site was $210^{\circ}$; thus, the ridge of the hill is approximately perpendicular to the flow. The figure shows that the agreement between calculated and observed winds is quite good for the two J-H models and for the NOABL model operated without optimization. For these models, the only area of substantial discrepancy occurs at anemometers R, S, T, and V, which are stationed on the lee side of the hill. (This discrepancy would have likewise been observed at anemometer $U$ had the anemometer been in service for this particular case.) These anemometers are immersed in the wake induced by the hill, and consequently the flow is very turbulent and phenomena such as flow separation may occur. That these phenomena cannot be adequately modeled by such physicaliy simple models may account for the models' poor performance in this area.

For case MF03d, the optimizing NOABL was tuned to only three stations, $B, C P$ and 2. As indicated in Table 4.2, of all the model applications to Askervein Hill, this particular model run had the largest RMSE $(0.232)$. This error is very much larger than the RMSE of the NOABL model run without optimization. (However, had a different illustrative case been chosen, for example MF02c, the optimizing NOABL model could be discussed in a much more favorable light!) Figure 4.2 shows that the error between calculated and observed winds was particularly large at several places on the hill, with the worst errors occurring on the lee side of the hill at the anemometers $R, S, T$, and V. These poor results may be improved somewhat by a different choice of tuning sites. For example, if the tuning sites are taken to be stations $A, C P, T$, and 2, the RMSE becomes 0.186 , an improvement over the former RMSE of 0.232 . Further improvement may result from the selection of even another set of tuning sites, but this is not a useful procedure, because one does not know in advance which sites to select to optimize the model's performance.

Qualitative features of the modeled flow for a wind direction of $210^{\circ}$ (i.e., case MF03d) are depicted by normalized speed contours overlaid on terrain contours, as shown in Figure 4.2. Because BZ only makes point predictions, a contour plot for this model is not included in this set of figures. The wind fields derived from the MS3DJH/3R model (Figure 4.2a) and the NOABL model, operated without optimization (Figure 4.2b), are similar and are consonant with what one would intuitively expect. The MS3DJH/3R model does show 
ASKERVEIN HILL

MS3DJH/3R - WIND DIRECTION: $210^{\circ}$

TERRAIN CONTOUR INTERVAL $=10 \mathrm{~m}$

NORMALIZED SPEED CONTOUR INTERVAL $=0.2$

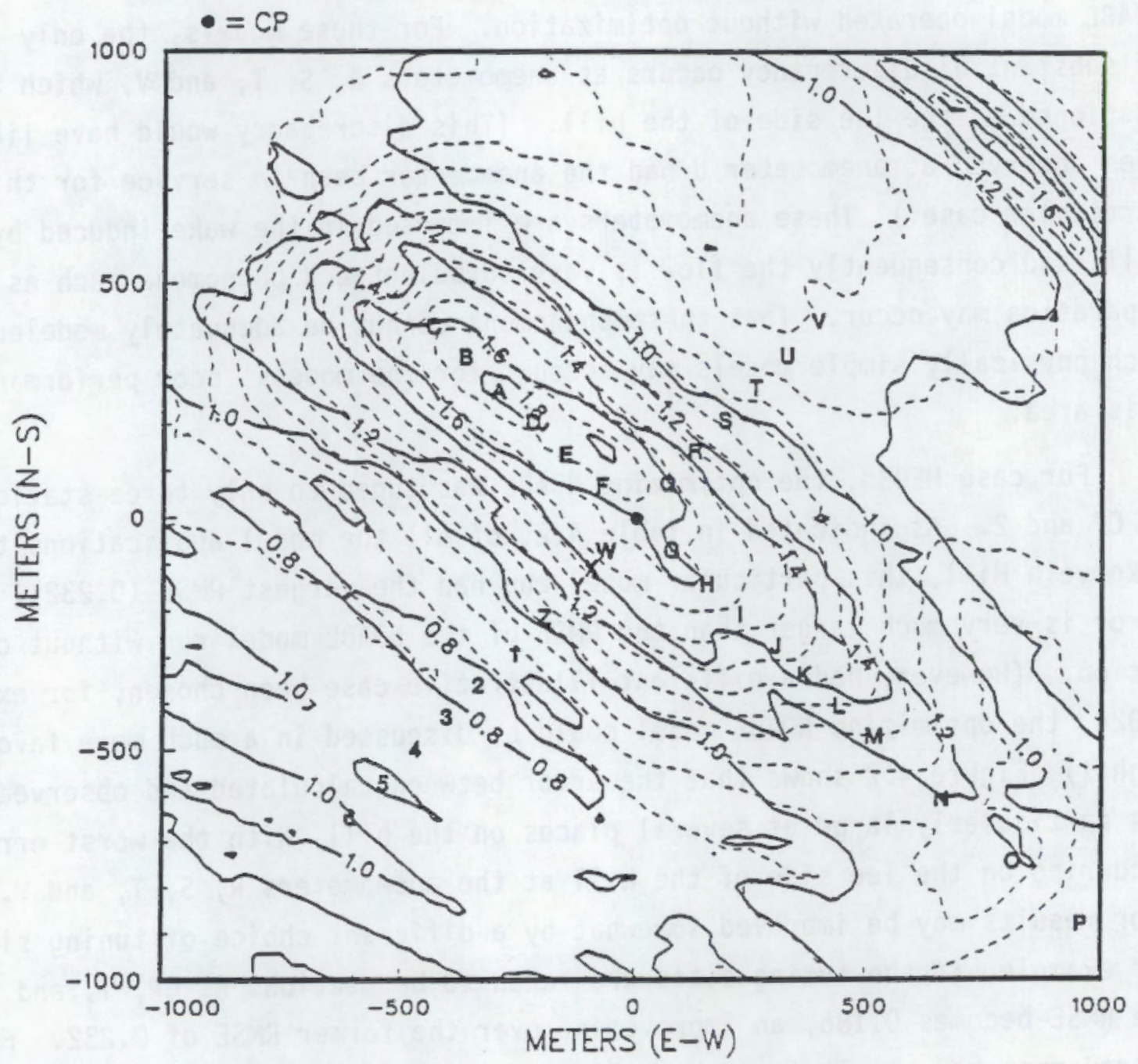

FIGURE 4.2a. Normalized Wind Speed Contours (solid) Derived from the MS3DJH/3R Model Overlaid on Askervein Hill Terrain Contours (dashed) for a Wind Direction of $210^{\circ}$. The normalized speed contour interval is 0.2 , and the terrain contour interval is $10 \mathrm{~m}$. 


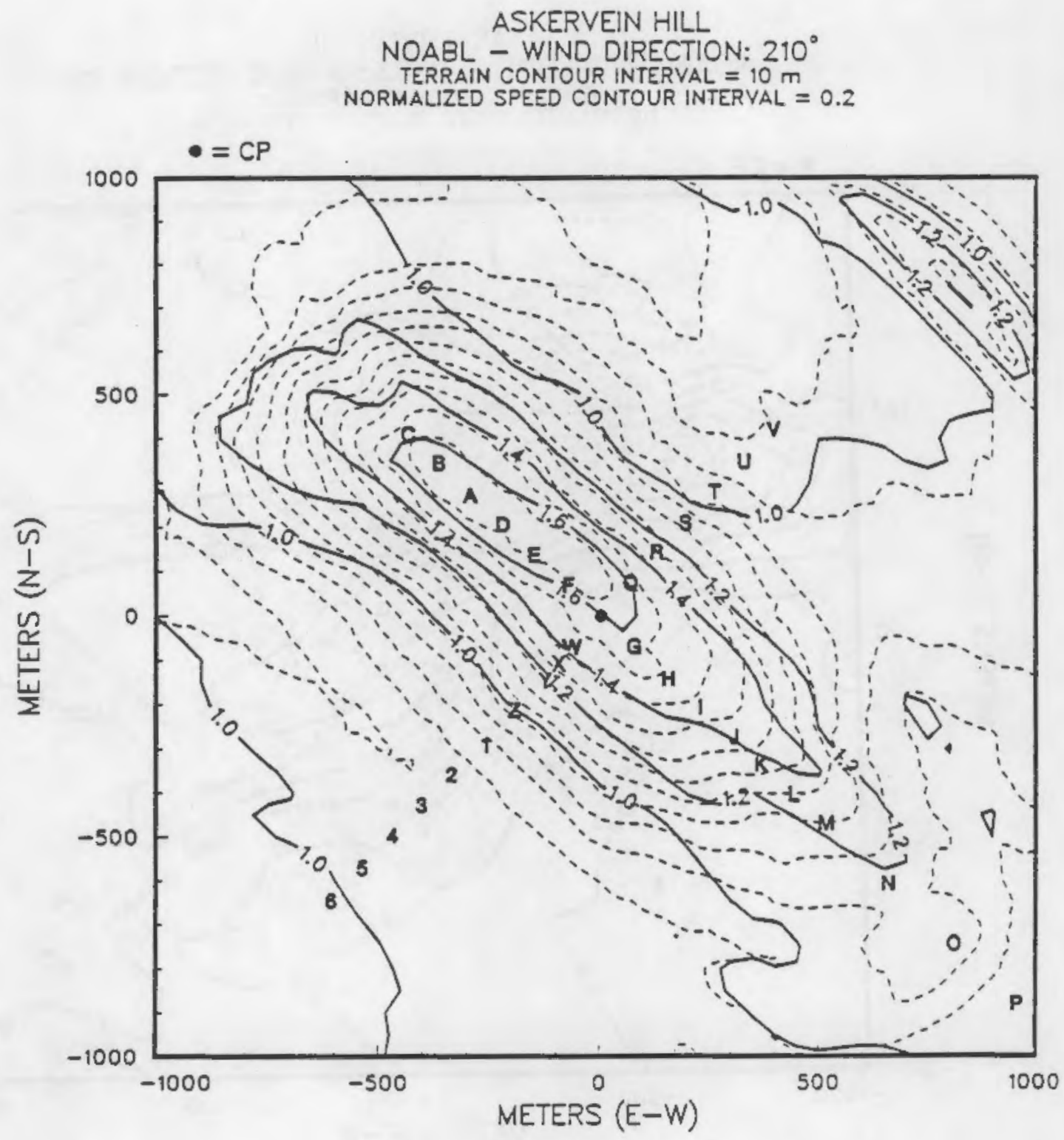

FIGURE 4.2b. Normalized Wind Speed Contours (solid) Derived from the NOABL Model Overlaid on Askervein Hill Terrain Contours (dashed) for a Wind Direction of $210^{\circ}$. The normalized speed contour interval is 0.2 , and the terrain contour interval is $10 \mathrm{~m}$. 


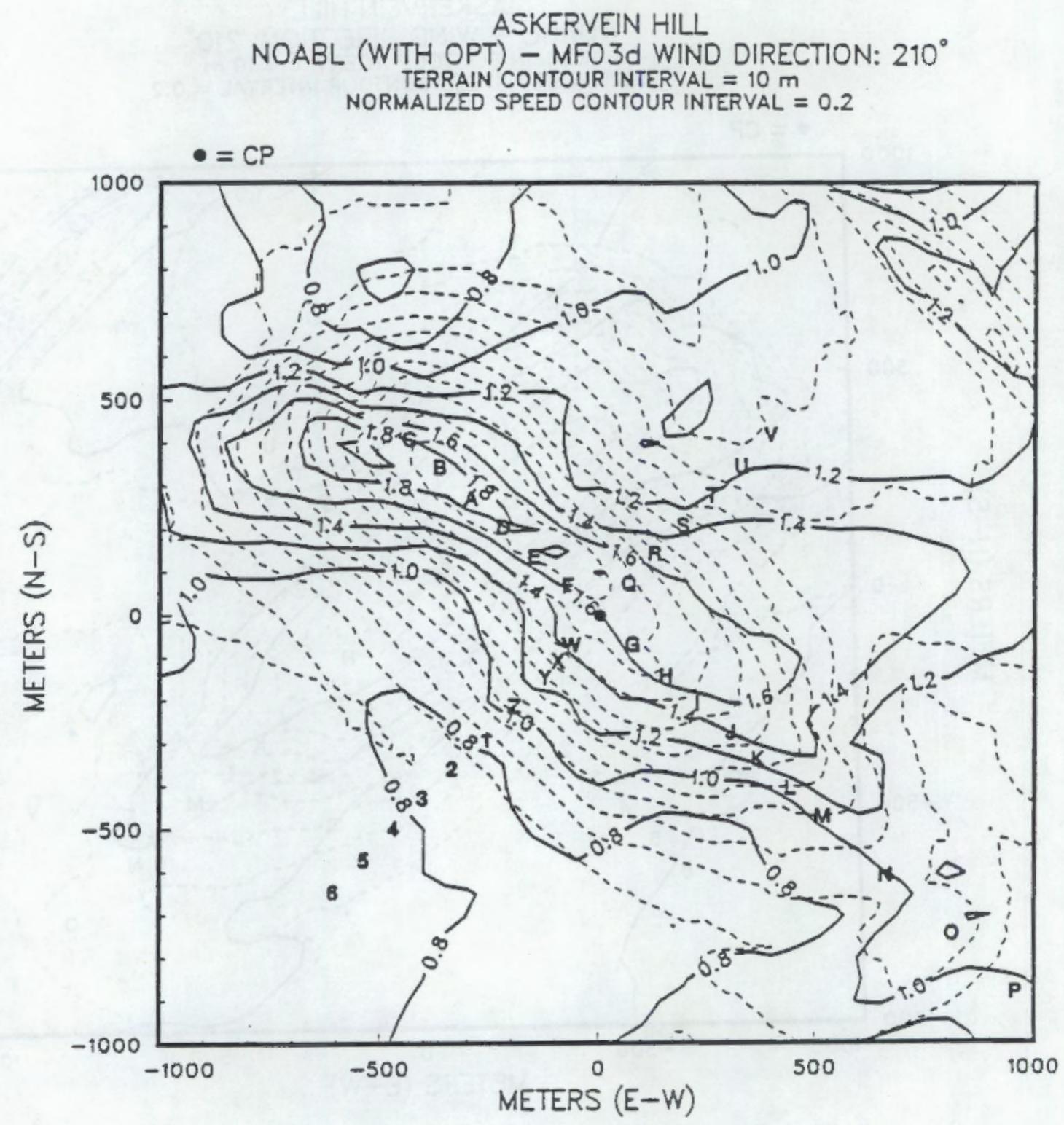

FIGURE 4.2c. Normalized Wind Speed Contours (solid) Derived from the Optimizing NOABL Model Overlaid on Askervein Hill Terrain Contours (dashed). The normalized speed contour interval is 0.2 , and the terrain contour interval is $10 \mathrm{~m}$. 
more wind variability over small length scales on the order of $100 \mathrm{~m}$ or less. Whether this variability occurs in fact cannot be determined by examining the wind observations from the existing net of anemometers because the distance between them is too large.

Additionally, the absence of this small-scale variability in the NOABL simulation may be caused by the coarser grid resolution specified for the model's finite difference grid. The spacing between grid points was set at $50 \mathrm{~m}$ for the NOABL run, which was exactly twice that of MS3DJH/3R $(25 \mathrm{~m})$. Thus, if the variability is real, the NOABL simulation would not be able to portray it as well as the MS3DJH/3R simulation.

The wind field from the optimizing NOABL model is shown in Figure $4.2 \mathrm{C}$ and is quite different than the other two wind fields; furthermore, the modeled field contains some features that seem physically unrealistic. For example, there is no physical mechanism that would explain the indentation of the normalized speed contours on the windward side of the hill to the southwest of stations $D, E$, and $F$, given that a steady flow is impinging on the hill from the southwest over a fetch of uniform surface roughness.

The overall performance of the models may be summarized by examining the skill of the models in predicting averaged normalized winds, where the average is over the six cases. The RMSE associated with this comparison, which we shall term as an 'average' RMSE, and the average prediction error, are listed in the bottom two lines of Table 4.2. The prediction errors are $8.4 \%$ (MS3DJH/3R), $7.9 \%$ (BZ), $9.1 \%$ (NOABL), and $10.1 \%$ (NOABL with optimization). The prediction errors are very close to one another, and it appears that on the average, no model is clearly superior to any of the others in predicting speeds over Askervein Hill.

This similarity in the models' overall performance is again evident in Figure 4.3, where scatterplots of averaged observed and model-derived normalized speeds are plotted for each model. With the exception of the stations $U, R, S$, and $T$ that are in the wake of the hill for four of the six cases (MF02c, MF02a, MF03d, MF05c), all models exhibit definite skill in predicting the flow over Askervein $\mathrm{Hill}$, and a clear discrimination between the high and low speed regions of the hill is possible. 

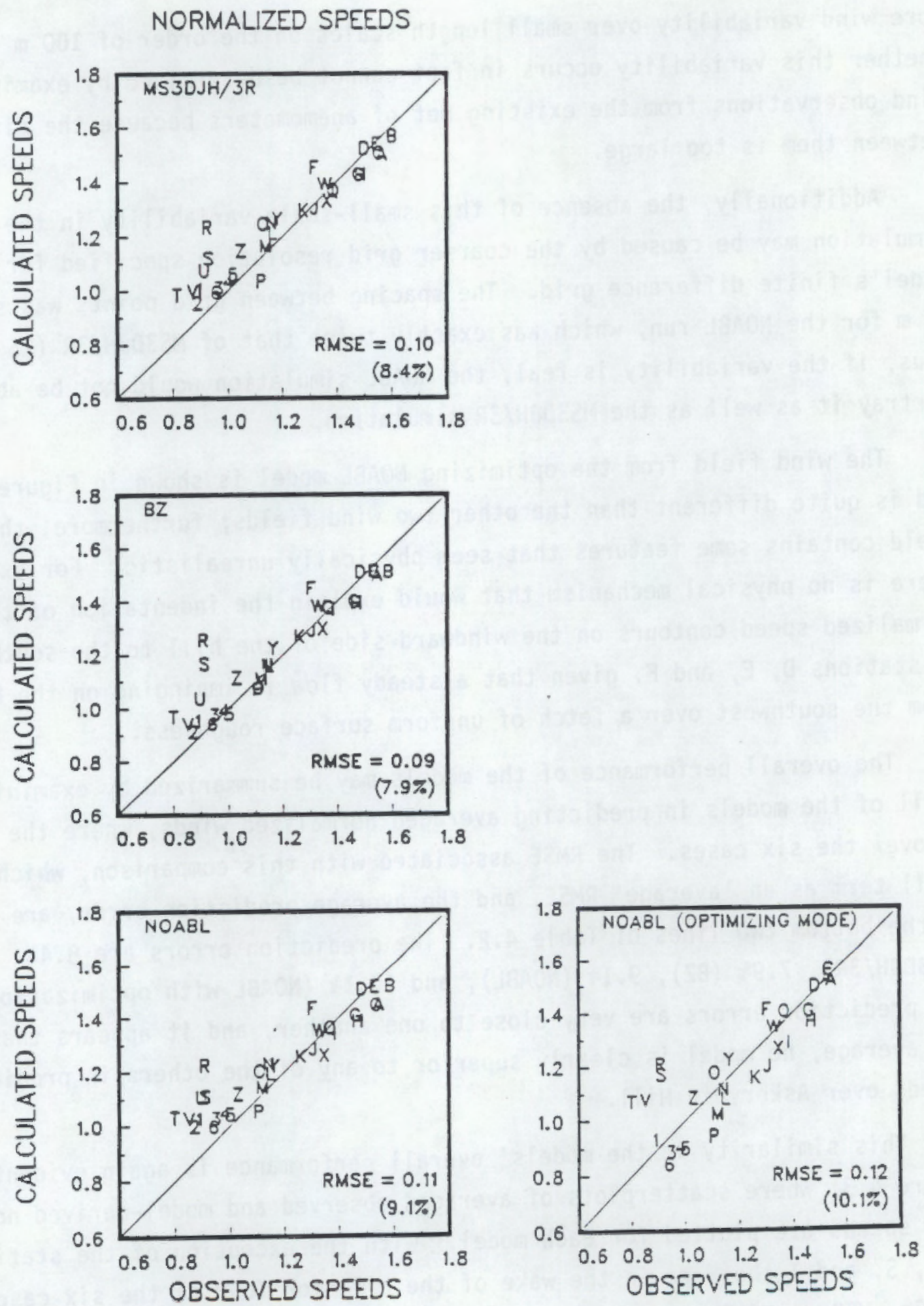

FIGURE 4.3. Model-Derived Normalized Speeds Plotted Versus the Observed Normalized Speeds Obtained from the Askervein Hill Data Set. The indicated speeds are averages over the six cases. 
In view of the large difference in formulation between mass-consistent and $\mathrm{J}-\mathrm{H}$ type models, it is initially surprising that the modeling results are so similar, and it is natural to enquire why this is so. One possible answer that seems quite reasonable is the following: of all the physical factors governing the relatively high-speed flow in complex terrain of moderate slope, mass-conservation plays the leading role. of course, in addition to massconservation, the calculated field must satisfy boundary conditions that correspond to the actual winds encountered at the edge of the modeling domain. Lateral boundary conditions for Askervein Hill are particularly simple, because the flow far away from the hill - the undisturbed flow - is essentially uniform. Thus, models that calculate wind field which satisfy these boundary conditions while conserving mass should provide reasonable flow simulations. Furthermore, the difference between simulations derived from different models should not be very large - if the conjecture about the predominant role of mass-conservation is correct.

\subsection{ALTAMONT PASS MODEL COMPARISONS}

For the Altamont Pass flow simulations, Table 4.3 lists the grid parameters for the NOABL and MS3DJH/3R. Also found in this table is the terrain contour interval specified for the BZ model; this interval is $30 \mathrm{~m}$ and is much larger than the 6-m interval designated for the Askervein Hill simulations. Because of the restriction on the number of contour lines and contour data points inherent to the $B Z$ model, one is faced with the usual trade-off: either the size of the zooming grid must be shrunk in order to retain a fine contour interval, or the terrain contour resolution must be decreased, thereby allowing the zooming grid to encompass more terrain. Both alternatives were tested, and it was found (surprisingly) that the combination of a larger area with a coarser terrain resolution yielded the best modeled winds.

The models were operated to simulate the mean monthly speed at 20 verification sites over the Altamont Pass modeling domain. These sites are indicated by the alphabetic characters in Figure 3.2. The numeric characters in the figure (1 through 6 ) denote the locations of sites whose wind observations were used for mode1 input. 
TABLE 4.3. Model Grid Parameters - Altamont Pass

\begin{tabular}{|c|c|c|}
\hline Model & Grid Spacing (m) & Grid Size \\
\hline MS3DJH/3R & 20 & $256 \times 256$ \\
\hline NOABL & 50 & $50 \times 50$ \\
\hline Model & $\begin{array}{l}\text { Terrain Contour } \\
\text { Interval (m) }\end{array}$ & \\
\hline
\end{tabular}

Wind observations contained within a modeling domain represent information that can contribute greatly to the accuracy of wind flow simulations. Any model that does not take advantage of this information could be handicapped in its ability to accurately simulate the winds. It is easy to handle temporal variations in the free-stream flow by segregating the observations into bins within which the speed and direction are approximately constant. The models are then run for a speed and direction characteristic for each bin, and an average flow field is determined by averaging these individual runs, weighted by their frequency of occurrence. This standard procedure is easily implemented by software associated with the $B Z$ and MS3DJH/3R models. Although the Altamont Pass wind regime is very unidirectional (recall the PDF shown in Figure 3.3 ), this procedure was nevertheless employed in an attempt to maximize the accuracy of the modeling results.

In the case where the free-stream flow is relatively constant in time, but may vary spatially, the manner in which the wind observations were used depends on the type of model. Mass-consistent models are designed to explicitly use input wind observations, which form the basis of the initial guess made prior to the mass-consistent adjustment. In general, the more input observations, the better the flow simulation. On the other hand, J-H models are limited in their ability to employ more than one wind observation at a time. These models assume that the modeling domain under consideration is immersed in a uniform free-stream flow. The uniform nature assumed for this ambient flow implies that only a single direction and speed can be associated with $\mathrm{it}$, and consequently $\mathrm{J}-\mathrm{H}$ type models are only capable of using a 
single observation, which is used to characterize the free-steam flow. Therefore, when the free-stream flow is not spatially uniform over the modeling domain, simulations derived from $\mathrm{J}-\mathrm{H}$ models could be seriously in error, because the assumption of a spatially uniform free-stream flow does not hold. However, in these instances the calculated fields derived from the J-H models may be improved through a post-processing of the simulated field that is based on the observations. This post-processing is not part of a J-H model, and it is up to the model user to invent a post-processing method. This report will present one such method developed by the author.

Before discussing the post-processing, it is enlightening to run all the models using just a single observation as input. The NOABL model cannot be operated in the optimizing mode with only one input station, so we set optimization aside for the time being and ran NOABL without optimization, with $\tau$ specified as 0 (neutral stability.) The single observation, which we shall call the reference site, is taken to be station 1 indicated on Figure 3.2. The other observations at sites $2-6$, which had originally been earmarked for model input, are now temporarily ignored. The results of these simulations, as depicted by RMSEs and associated prediction errors between mode1derived and actual mean monthly speeds at the 20 verification sites, are shown in Table 4.4; furthermore, the comparison between calculated and observed winds is depicted by scatterplots in the left-hand column of Figure 4.4. Obviously, the error between observed and simulated winds at the 20 sites is very large with prediction errors about $25 \%$. In fact, if one were to assume that the wind was uniform over the modeling domain, and equal to the speed at the reference site, then the prediction error would be $20 \%$, somewhat less than any of the models' errors. Thus, for this situation, one's knowledge of the wind field is degraded by the use of models!

So why is the error so large? Some of the large magnitude of the error is not due to the models but is merely an artifact of the choice of reference site. For the NOABL and MS3DJH/3R models, whose output is a wind field over the entire modeling domain, the calculated fields are normalized by forcing the model speed to equal the observed speed at this site. Similarly, the reference site also normalizes the calculated speeds of $B Z$, because it serves 
TABLE 4.4. RMSEs $(\mathrm{m} / \mathrm{s})$ and Prediction Errors $(\%)$ for the Altamont Pass Modeling Simulations. The prediction errors are in the parentheses to the immediate right of the RMSEs.

Number of

Input Wind

Stations

1

6

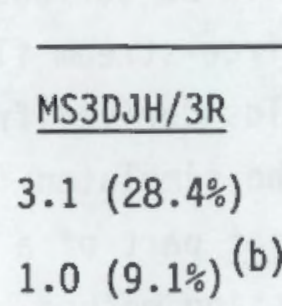

Model

$\begin{array}{ll}\frac{B Z}{2.7(24.0 \%)} & \frac{N O A B L}{3.1(28.1 \%)} \\ 1.1(10.0 \%)(b) & 1.9(16.9 \%) \\ & 1.0(8.9 \%)(c)\end{array}$

Optimizing NOABL

(a) The optimizing NOABL model cannot be operated with only one input wind observation.

(b) Wind fields calculated by $\mathrm{J}-\mathrm{H}$ models require post-processing when more than one wind observation is available.

(c) Results using six stations for input and post-processing of the model output.

as the site used to derive the 'windatlas' necessary for the operation of this model. But this site has one of the highest speeds in the modeling domain, and therefore most of the calculated speeds are uniformly too high, as is most apparent in the scatterplots of Figure 4.4. If another reference site were chosen, whose speed were closer to the mean of all the speeds, the error would be reduced. One can visualize this reduction by a uniform lowering of all the speeds in the scatterplot. The calculated speeds would then lie closer to the $45^{\circ}$ line that indicates a perfect match between simulated and observed winds. Note that even if this uniform lowering of speeds were undertaken, the models would still not do well in predicting the trend in wind speeds over the site, and the results must still be considered poor.

So we must again ask why the results are so poor and consider the meteorology over the modeled area. Unlike Askervein $\mathrm{Hill}$, where the free-stream flow is uniform, the Altamont Pass free-stream flow accelerates as the flow moves downhill. This acceleration is clearly evident in the wind observations. For example, wind speeds measured at stations on the upslope side of the modeled area, for example, N, O, P, and 5, are much lower than speeds measured on the downslope side at, for example, stations A, I, and 1 (see Table 3.2). Physically this acceleration appears to be caused by the cool, relatively 
1 STATION
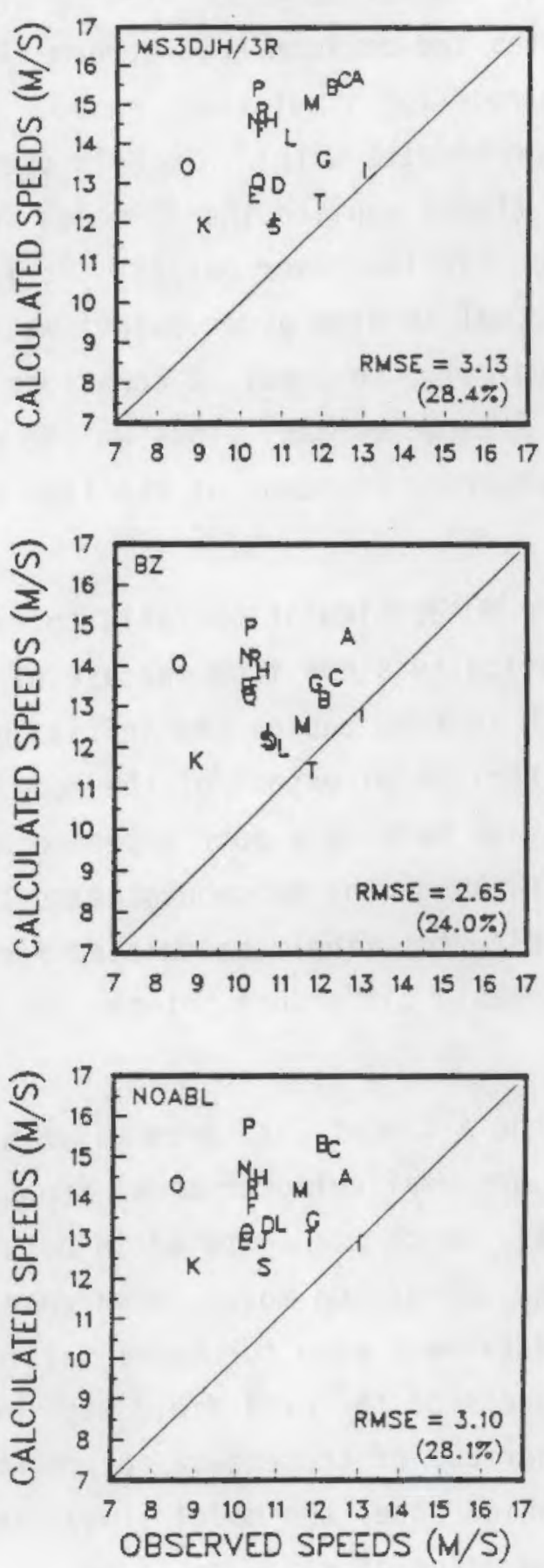

6 STATIONS
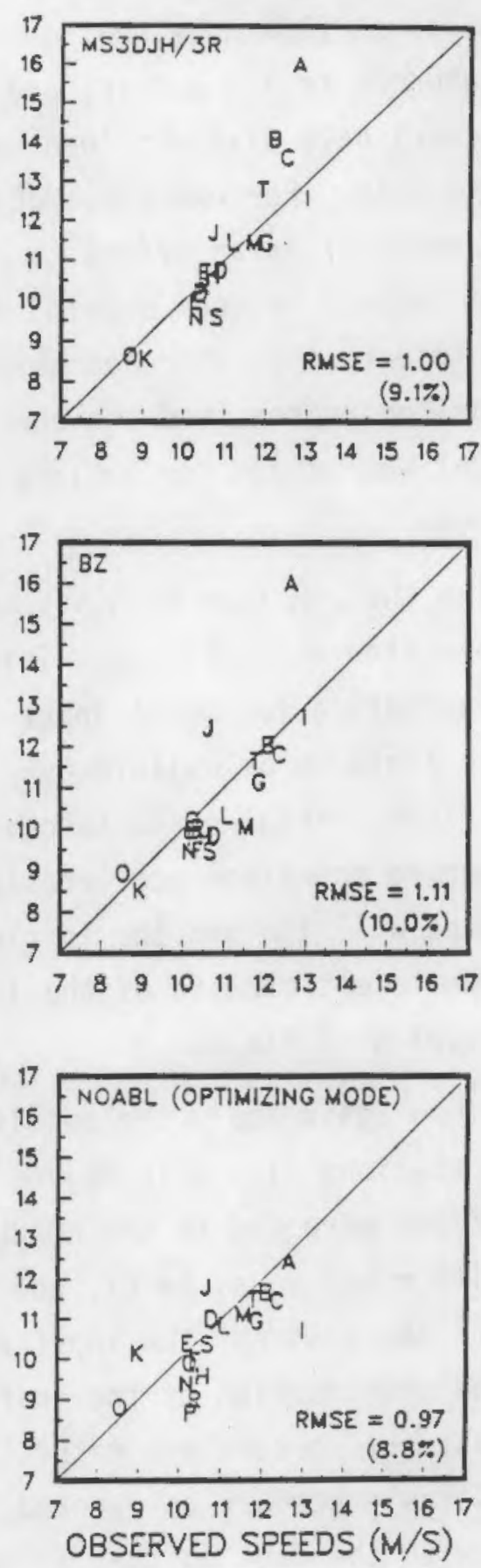

FIGURE 4.4. Model-Derived Speeds $(\mathrm{m} / \mathrm{s})$ Plotted Versus Observed Speeds $(\mathrm{m} / \mathrm{s})$ Obtained from the Altamont Pass Data Set. The lefthand column shows modeling results when only one station was used for model input. The results in the right-hand column were obtained by using six stations either for model input (NOABL) or for post-processing of the calculated wind fields (M53DJH/3R, BZ). 
dense marine air flowing over the pass, similar to water flowing over a dam. This apparent flow acceleration violates the uniform free-stream flow assumption inherent to $\mathrm{J}-\mathrm{H}$ models, and poor modeling simulations ensue. Other researchers have also obtained inferior results with $\mathrm{J}-\mathrm{H}$ models used in Altamont Pass. For example, McCarthy (1989) applied the BZ model (within the WAsP framework) in an effort to predict turbine power output. He found that the discrepancy between modeled and actual turbine power output was relatively small close to the reference meteorological tower, but at downslope locations, the model underpredicted the power by a large margin. Thus we see again that the model was unable to simulate the observed speed-up of the flow as it moves downstream.

Like the J-H flow simulations, the NOABL simulation fails to capture the downslope flow acceleration. This difficulty stems from the use of only one wind observation for model input, which in turn causes the initial guess of the wind field to be uniform over the horizontal extent of the modeling domain. This uniform initial guess is obviously an extremely poor representation of the observed downslope acceleration. Although the subsequent mass-consistent adjustment will improve the initial field, the final, calculated field will remain deficient because of the irredeemable difference between the observed and initial wind fields.

We now again apply the models to the Altamont Pass area assuming that all six stations (1 - 6 in Figure 3.3 ) are available for model input. All six observations were fed to the NOABL model, which was operated in both the normal mode (with $\tau$ set equal to 0 ), and in the optimizing mode. When operated in either of these modes, the input wind data were used for model initialization, i.e., the construction of the initial guess of the wind field made prior to the adjustment to conserve mass. Further use of these data occurs when the optimization procedure is invoked, in which case, the model simulation is 'tuned' with the data so that an optimum value of $\tau$ may be found.

The MS3DJH/3R and BZ simulations are the same as the single-station simulations previously discussed, except now these simulations will be postprocessed to conform as closely as possible to the observations. It again must be reemphasized that this post-processing is something that is done after 
the model simulations are completed, and it is based on the user's ingenuity to devise a method that achieves reasonable results.

We now describe the post-processing applied to simulations of MS3DJH/3R and $B Z$. The crux of this procedure is to determine a correction factor, $c(x, y)$ that multiplies the simulated speed at any point in modeling domain, $s_{c}(x, y)$, to give a corrected simulated speed, $s f(x, y)$ :

$$
s_{f}(x, y)=c(x, y) \cdot s_{c}(x, y) .
$$

For a specified height above the terrain surface, this correction is applied to all points of interest in the modeling domain to find a corrected wind field. $c$ is assumed to be a linear function of $x$ and $y$, the horizontal terrain coordinates, and is chosen such that at the observation sites, the leastsquares difference between the observed and corrected simulated wind speeds is minimized. Determination of $c$ is thus a straightforward problem in linear least-squares, a process that we now briefly describe. We first write $c$ explicitly as a linear function of $x$ and $y$ :

$$
c(x, y)=a_{1}+a_{2} x+a_{3} y
$$

where $a_{1}, a_{2}$, and $a_{3}$, are constants that will be derived from the leastsquares procedure. Let $x_{0}^{i}$ and $y_{0}^{i}$ denote the locations of $N$ observation sites, where the index $i$ runs from 1 to $N$. ( $N$ will be 6 for the application at hand.) We require the minimization of the sum of the squares, $S\left(a_{1}, a_{2}, a_{3}\right)$, of the difference between the observed and corrected speeds:

$$
\begin{aligned}
S\left(a_{1}, a_{2}, a_{3}\right) & =\sum_{i=1}^{N}\left(s_{0}\left(x_{0}^{i}, y_{0}^{i}\right)-s_{f}\left(x_{0}^{i}, y_{0}^{i}\right)\right)^{2} \\
& =\sum_{i=1}^{N}\left(s_{0}\left(x_{0}^{i}, y_{0}^{i}\right)-\left(a_{1}+a_{2} x_{0}^{i}+a_{3} y_{0}^{i}\right) \cdot s_{c}\left(x_{0}^{i}, y_{0}^{i}\right)\right)^{2}
\end{aligned}
$$


where $s_{0}\left(x_{0}^{i}, y_{0}^{i}\right)$ is the observed speed at the observation station $i$. The sum of squares, $S\left(a_{1}, a_{2}, a_{3}\right)$, has been written as function of the unknown coefficients $a_{1}, a_{2}$, and $a_{3}$, and these coefficients are determined so that $S$ is minimized using standard least-squares techniques. Once the coefficients are known, the correction factor may be found at all points of interest in the modeling domain using Equation 4.3.

This very simple post-processing method is, in effect, a multiplication of the calculated field by the coefficient $a_{1}$, coupled with a tilting of the field as represented by $a_{2} x+a_{3} y$ term. Clearly this procedure has the potential for producing disastrous results, particularly at locations away from the wind observation sites. For example, for sufficiently large $x$ and $y$ the coefficient $c(x, y)$ may become zero and even negative and, consequently, the "corrected" winds will bear no resemblance to reality! (Such an egregious error argues against the general application of this post-processing scheme.) We also note in passing that the corrected field may no longer conserve mass.

Using the six wind observations, the model simulations of BZ and MS3DJH/3R were post-processed by the method described above. The normal and optimizing NOABL models were run using all six observations as input. The RMSEs and predictions errors connected with these runs are shown in Table 4.4. The prediction errors are $9.1 \%$ and $10.0 \%$ for the MS3DJH/3R and BZ models, respectively, and $8.9 \%$ and $16.9 \%$ for the NOABL model, run with and without optimization. These errors have been significantly reduced over the runs associated with just one station. Scatterplots of these modeling results are shown in the right-hand column of Figure 4.4 and in the top panel of Figure 4.5; the improvement is again obvious. In fact, the simulations derived from the $\mathrm{J}-\mathrm{H}$ models would be very good if it weren't for station $A$, where the discrepancy between the observations and the calculated speed is large. If one excludes the unoptimized NOABL simulation, then the overall Altamont Pass results are reminiscent of those of the Askervein Hill simulations, that is, the performance of the models is nearly identical.

Because the post-processing greatly improved the $\mathrm{J}-\mathrm{H}$ simulations, it is tempting to apply this procedure to the unoptimized NOABL simulation in an attempt to reduce rather large prediction error, $16.9 \%$, associated with this simulation. The results of the post-processing are shown in the bottom panel 

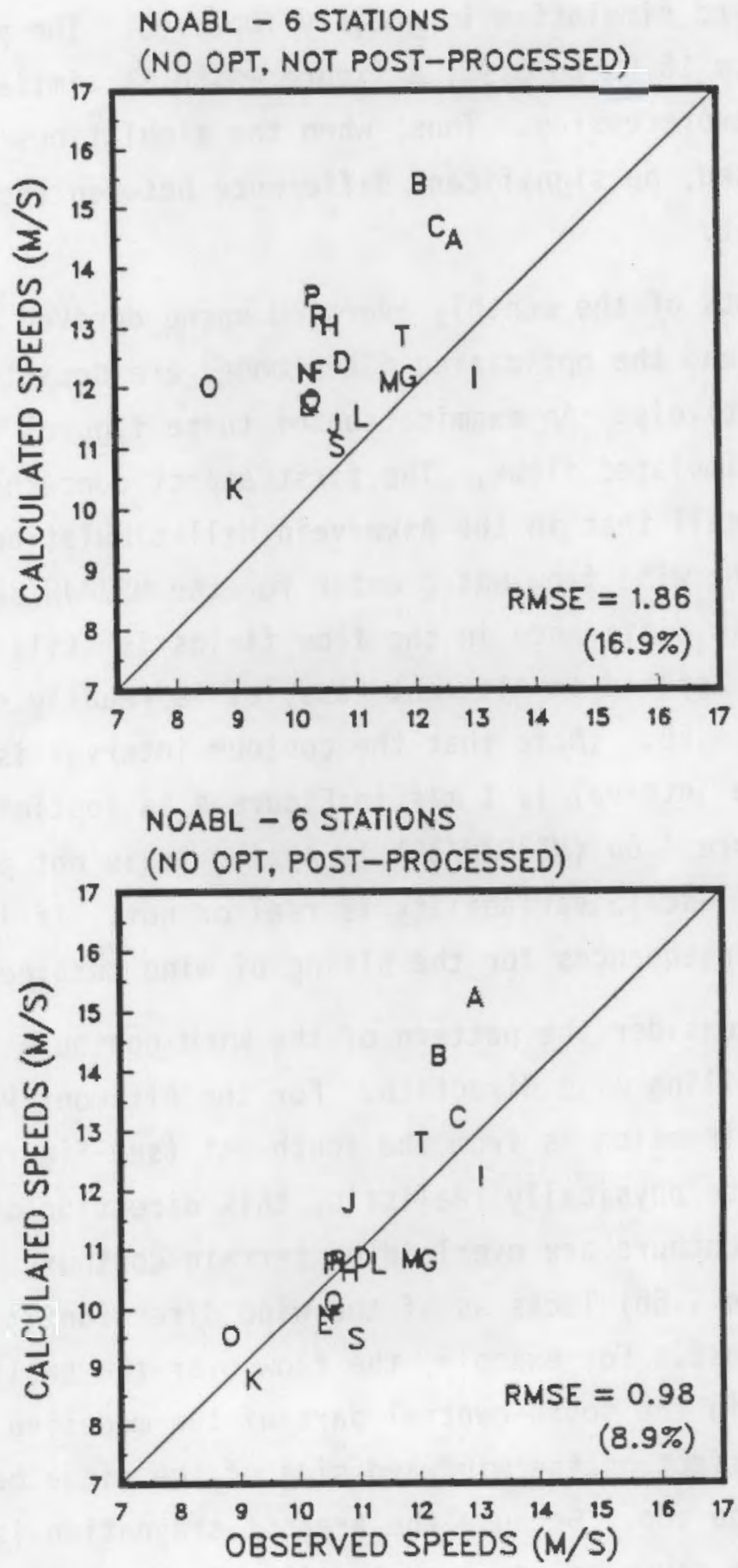

FIGURE 4.5. NOABL-Derived Speeds $(\mathrm{m} / \mathrm{s})$ Plotted Versus Observed Speeds $(\mathrm{m} / \mathrm{s})$, With and Without Post-processing. The calculated speeds in the upper panel are from an unoptimized NOABL simulation that employed six stations for model input. The lower panel is the same as the upper panel except the model simulation is now post-processed. 
of Figure 4.5, in which it is seen that the agreement between the data and the post-processed simulation is greatly improved. The prediction error has been reduced from $16.9 \%$ to $8.9 \%$, a figure which is similar to that of the J-H models with post-processing. Thus, when the simulations of all three models are post-processed, no significant difference between the performance of the models is evident.

Contour plots of the monthly averaged speed derived from MS3DJH/3R (and post-processed) and the optimizing NOABL model are depicted in Figures 4.6a and $4.6 \mathrm{~b}$, respectively. An examination of these figures reveals two important aspects of the simulated flows. The first aspect concerns the small-scale variability. Recall that in the Askervein Hill simulations, the small-scale variability of the wind flow was greater for the MS3DJH/3R model than for the NOABL model. This difference in the flow fields is still unmistakable when these models are applied to Altamont Pass, as is readily seen by comparing Figures $4.6 \mathrm{a}$ and $4.6 \mathrm{~b}$. (Note that the contour interval is not the same for both figures; the interval is $1 \mathrm{~m} / \mathrm{s}$ in Figure $4.6 \mathrm{a}$ (optimizing NOABL model) and $2 \mathrm{~m} / \mathrm{s}$ in Figure 4.6b (MS3DJH/3R).) Again, it is not possible to determine whether this small-scale variability is real or not. If it is real, it would have important consequences for the siting of wind turbines.

Second, we consider the pattern of the wind contours and their relationship to the prevailing wind direction. For the Altamont Pass wind data set, the predominant direction is from the southwest (see Figure 3.3). If a wind simulation is to be physically realistic, this direction should manifest itself when wind speed contours are overlaid on terrain contours. The MS3DJH/3R simulation (Figure $4.6 \mathrm{~b}$ ) looks as if the wind direction is from the proper direction, southwest. For example, the flow over the small ridge between stations $B$ and $C$ in the south-central part of the modeling domain is reduced by a stagnation effect on the windward side of the ridge before being accelerated over the ridge top. Because the area of stagnation is oriented toward the southwest, one may conclude that the flow is from this direction. In contrast, the prevailing wind direction is not strongly apparent in the optimizing NOABL simulations depicted in Figure 4.6a. If one attempted to determine the wind direction from the areas of stagnation, this task would be difficult, because no clear stagnation areas are evident. Therefore, the MS3DJH/3R 
simulation indicates the prevailing direction much more clearly than the NOABL simulations, which makes MS3DJH/3R flow fields appear to be more physically plausible.
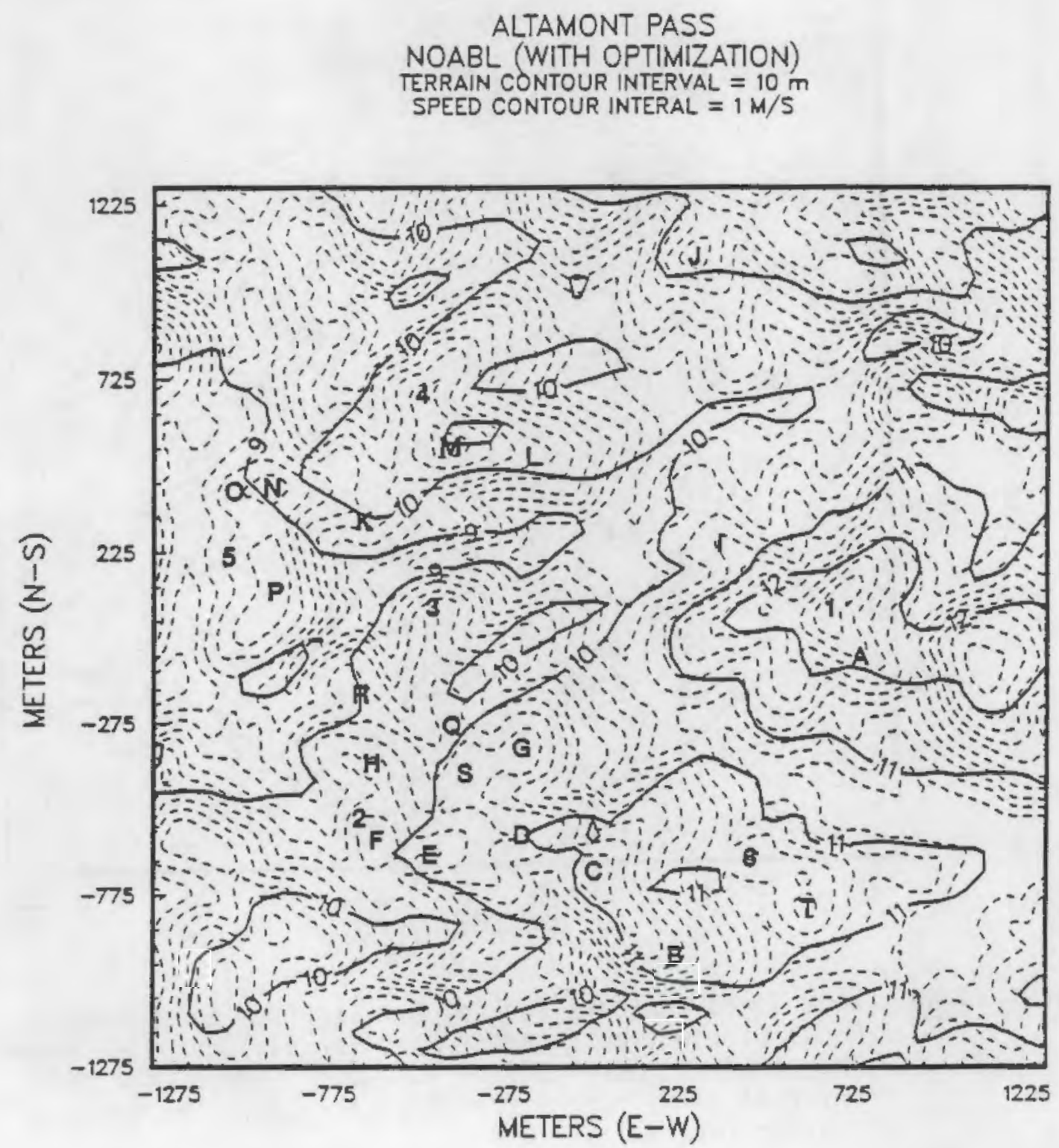

FIGURE 4.6a. Wind Speed Contours (solid) Derived from the Optimizing NOABL Model Overlaid on Altamont Pass Terrain Contours (dashed). The speed contour interval is $1 \mathrm{~m} / \mathrm{s}$, and the terrain contour interval is $10 \mathrm{~m}$. 


\section{ALTAMONT PASS \\ MS3DJH/3R \\ TERRAIN CONTOUR INTERVAL $=10 \mathrm{~m}$ \\ SPEED CONTOUR INTERAL $=2 \mathrm{~m} / \mathrm{S}$}

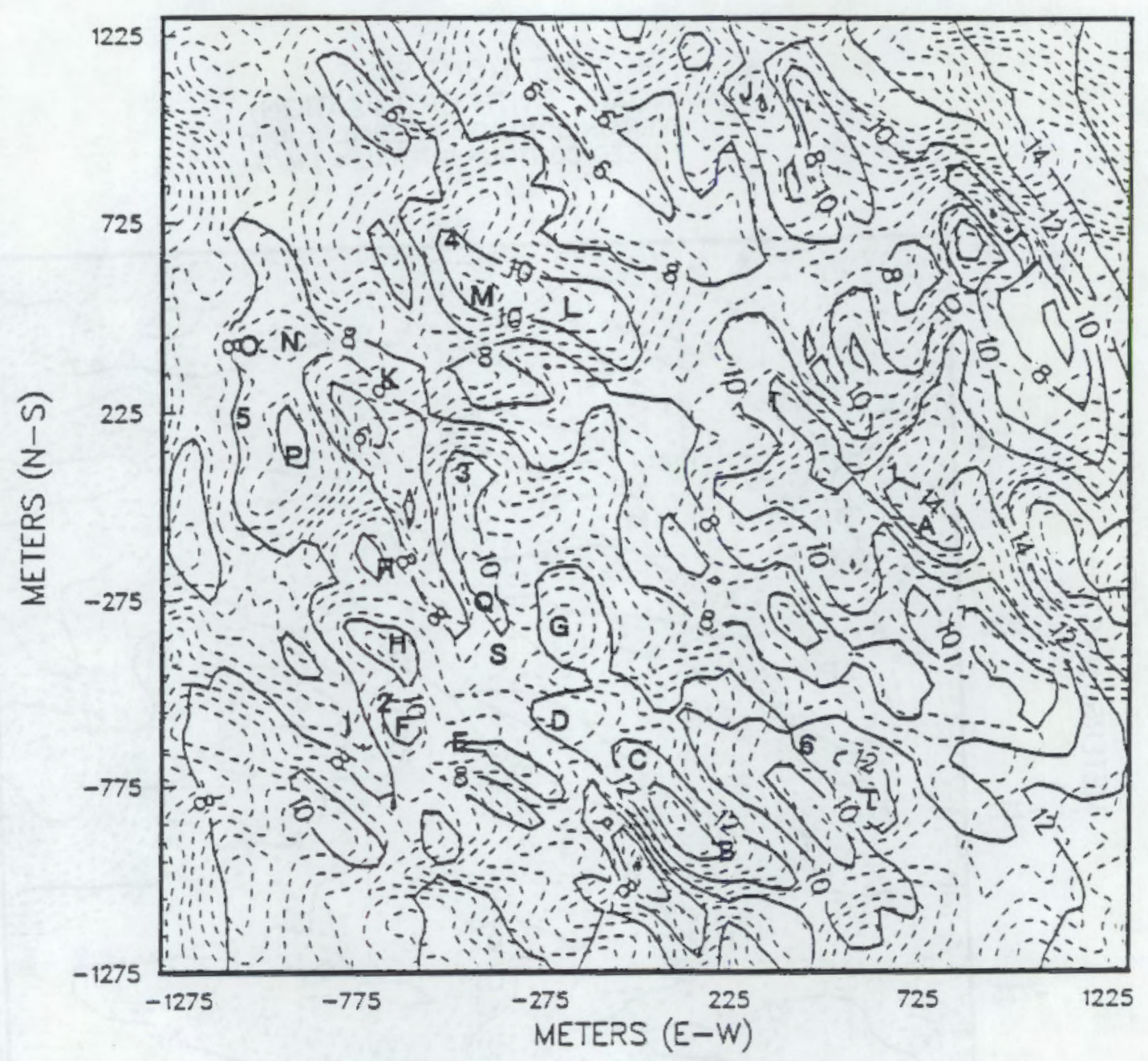

FIGURE 4.6b. Wind Speed Contours (solid) Derived from the MS3DJH/3R Model Overlaid on Altamont Pass Terrain Contours (dashed). The speed contour interval is $2 \mathrm{~m} / \mathrm{s}$. (Note that this interval is different from Figure 4.5a.) The terrain contour interval is $10 \mathrm{~m}$. 


\subsection{COSTS ASSOCIATED WITH MODEL USAGE}

Given a number of models that exhibit similar degrees of skill in predicting winds, those models that are both inexpensive to operate and easy to use will have the greatest likelihood of being used by the wind energy community. With this in mind, we briefly examine the "ease of use" and the expenses associated with operating the models. The modeling costs can be broken down into two categories: first, the labor required to run a mode 1 including the cost of digitizing the terrain needed for model input, and second, the computer time required to run the model. This section will not assign monetary values to these expenses, rather it will provide an idea of the relative costs of model operation.

Evaluating the "ease of use" of a model is a subjective exercise that depends upon the model user's experience and taste. All three models are supplied with user's guides that describe how to operate the models. The author had no previous experience in operating either the MS3DJH/3R or BZ models, but found that their user's guides provide enough information so that the models could be installed and subsequently operated on a personal computer with little difficulty and in a reasonable amount of time. Like the other two models, NOABL is easy to use. All three models can be run without a mastery of their theoretical basis; however, the usual caveat holds: users who are cognizant of the theory are less likely to make blunders in either the operation of the models or the interpretation of the model results.

One large difference between the operation of J-H models and the NOABL model is the amount of terrain that must be digitized. $\mathrm{J}-\mathrm{H}$ models that are cast in rectangular coordinates (MS3DJH/3R) use a Fourier transform technique to solve the governing equations. The periodic boundary conditions inherent to the transform technique and the necessity that the perturbation quantities vanish at a distance far away from the area over which speeds are to be calculated require that the modeled area be surrounded by a flat plain and transition zone between the plain and the modeled area. Therefore, not only must terrain be digitized within the area where an estimate of the winds is desired, but additional terrain must be digitized for the transition zone, which may equal or exceed the area of the modeling domain. Although the BZ model uses 
polar rather than rectangular coordinates, considerations analogous to those mentioned above demand that the outer model radius be distant from the model's origin, and it is wise to digitize a large expanse of terrain so that the model may work well. It has been the author's experience that accurate terrain digitization is a tedious and time-consuming process. The need for digitized terrain contours beyond that required for the NOABL model represents a major source of inconvenience for the users of $\mathrm{J}-\mathrm{H}$ models that cannot be ignored.

The computer time necessary for the operation of the models depends upon whether the model calculates an entire wind field, as do the MS3DJH/3R and NOABL models, or whether the model calculates the wind at a single point, as does the $B Z$ model. The focus of $B Z$ on a single point permits a very rapid execution time, which takes less than a minute for each point. For the data sets considered here, which consist of only about 30 points, model-derived speeds at these points can be calculated relatively quickly.

In contrast, the other two models calculate a wind field, and consequently their computer execution time is larger. Table 5.1 lists the relative computer time for the application of these models to Askervein Hill and Altamont Pass. MS3DJH/3R requires the least amount of time, followed by the NOABL model operated without optimization. The optimizing NOABL model consumes the greatest amount of time by a wide margin. This is not necessarily an expensive proposition when running the model on a desk-top computer, where the processing charges are not explicitly accounted for. However, the large amount of time for some runs - up to a day and a half - will tie up the computer, not to mention the strain on one's patience!

In summary, four important points may be made about the cost of operating the models. First, all three are reasonably easy to use. Second, the J-H models, $\mathrm{BZ}$ and $\mathrm{MS} 3 \mathrm{DJH} / 3 \mathrm{R}$, require about twice the amount of digitized terrain as the NOABL model, and the cost of this extra terrain may compose a significant portion of the operating cost of $\mathrm{J}-\mathrm{H}$ models. Thirdly, the cost of this additional terrain is partially offset by the lower requirements for computer time of the J-H models. This lower cost is particularly true when the operating time of $M S 3 D J H / 3 R$ or $B Z$ is compared with that of the optimizing NOABL model. Finally, it must be again emphasized that $B Z$ computes the wind speed only at a single point whereas the other models simulate an entire wind field. 
Therefore if one wishes to calculate a wind field over, say, a 40 by 40 grid, the BZ model would need to be operated 1600 times - an activity that could be quite tedious.

TABLE 5.1. Relative Computer Time for Model Operation. The BZ model is not included in this table because it only calculates the wind at a single point.

\begin{tabular}{ccc} 
Askervein Hill & Model & $\begin{array}{c}\text { Relative } \\
\text { Computer Time }\end{array}$ \\
\cline { 2 - 3 } & $\begin{array}{c}\text { MS3DJH/3R } \\
\text { (no optimization) }\end{array}$ & 1 \\
(with optimization) & 10
\end{tabular}

Altamont Pass

$\begin{array}{cc}\text { MS3DJH/3R } & 1 \\ \text { NOABL } & 3 \\ \text { (no optimization) } & \\ \begin{array}{c}\text { NOABL } \\ \text { (with optimization) }\end{array} & 70\end{array}$


,

. 


\subsection{CONCLUSIONS}

This study has evaluated the performance of three micrositing models to simulate the winds in complex terrain. Two of these models, MS3DJH/3R and $B Z$, are descendants of $\mathrm{J}-\mathrm{H}$ theory, while the third, NOABL, is a massconsistent model. The NOABL model was operated in both optimizing and normal modes. The models were evaluated by comparing model-derived simulations of the wind to actual wind data collected from two areas of complex terrain. The topography of these two areas differs considerably. Askervein $\mathrm{Hill}$ is an isolated hill of moderate slope surrounded by a flat plain, while in contrast, the Altamont Pass modeling domain is very hilly.

This study has found that the overall performance of the models is about the same. When the models were applied to Askervein Hill, the errors in the prediction of averaged winds were in a range of about 8 to $10 \%$ for all models. Wind speed prediction errors for Altamont Pass were sensitive to the number of wind observations available for either model input, in the case of massconsistent models, or post-processing of the model simulations, in the case of J-H models (or the NOABL model operated without optimization). This postprocessing was necessary because $\mathrm{J}-\mathrm{H}$ models are not designed to accept more than one input wind observation. With only one wind input wind station employed for model input, all models performed poorly and exhibited wind speed prediction errors of about $25 \%$. Using six wind input stations reduced the errors to about 9 to $10 \%$. Errors of this magnitude are essentially identical to those found for the Askervein Hill model simulations. The greatly improved model simulations that follow from the use of the six wind observations underscore the necessity for wind data at more than one point in some modeling situations.

All the models are easy to use and may be operated on a desktop computer. $\mathrm{J}-\mathrm{H}$ models require the least amount of computer time while the computer time of the optimizing NOABL model may be up to 100 -fold greater that the J-H models. J-H models require more digitized terrain than mass-consistent models, and this may represent a significant extra cost of their operation.

The question of whether the errors quoted in this report are low enough so as to encourage the use of these models by the wind energy industry remains 
unanswered. This issue must be decided upon by those closely involved with wind turbine micrositing. 


\subsection{REFERENCES}

Barnard, J. C., H. L. Wegley, and T. R. Hiester. 1987. "Improving the Performance of Mass-Consistent Numerical Models Using Optimization Techniques." J. Clim. and App 1. Meteor. 26(6):675-686.

Barnard, J. C., and A. Germain. 1988. Verification of the Optimizing NOABL Model Using a Spatially Dense Wind Data Set. PNL-6543, Pacific Northwest Laboratory, Richland, Washington.

Barton, S. M., and R. S. Hunter. 1988. "A Practical Comparison of Various Resource Prediction Techniques." Presented at the European Community Wind Energy Conference, June 6-10, 1988, Herning, Denmark.

Jackson, P. S., and J. C. R. Hunt. 1975. "Turbulent Wind Flow Over A Low Hi11." Quart. J.R. Meteorol. Soc. 105:383-395.

Lalas, D. P., M. Tombrou, and M. Petrakis. 1988. "Comparison of the Performance of Some Numerical Wind Energy Siting Codes in Rough Terrain." Presented at the European Community Wind Energy Conference, June 6-10, 1988, Herning, Denmark.

Mason, P. J., and R. I. Sykes. 1979. "Flow Over an Isolated Hill of Moderate Slope." Quart. J. R. Meteorol. Soc. 105:383-395.

McCarthy, E. F. 1989. "Evaluation of the Wind Atlas Approach in Altamont Pass, California, for Wind Energy Assessment." Presented at the European Wind Energy Conference, July 10-13, 1989, Glasgow, Scotland.

Pennel1, W. T. 1982. An Evaluation of the Role of Wind Field Models in Wind Turbine Siting. PNL-4317, Pacific Northwest Laboratory, Richland, Washington.

Sempreviva, A. M., I. Troen, and A. Lavagnini. 1986. "Modelling of Wind Power Potential in Sardinia." Presented at the European Wind Energy Conference and Exhibition, October 7-9, 1986, Rome, Italy.

Sherman, C. A. 1978. "A Mass-Consistent Model for Wind Fields Over Complex Terrain." J. Appl. Meteor. 17:312-319.

Taylor, P. A., J. L. Walmsley, and J. R. Salmon, 1983. "A Simple Model of Neutrally Stratified Boundary-Layer Flow Over Real Terrain Incorporating Wavenumber-Dependent Scaling." Boundary-Layer Meteorol. 26:169-189.

Taylor, P. A., and H. W. Teunissen. 1983. ASKERVEIN'B2: Report on the September/October 1982 Experiment to Study Boundary-Layer Flow Over Askervein, South Uist. Research Report MSR̈B-83-8, Atmos. Environ. Service, Downsview, Ont., Canada (ASK82).

Taylor, P. A., and H. W. Teunissen. 1985. The Askervein Hill Project: Report on the September/0ctober 1983 Main Field Experiment. Internal Report MSRB84-6, Atmos. Environ. Service, Downsview, Ontario, Canada (ASK83). 
Taylor, P. A., and H. W. Teunissen. 1987. "The Askervein Hill Project: Overview and Background Data." Boundary-Layer Meteorol. 39:15-39.

Traci, R. M., G. T. Phillips, and P. C. Patnaik. 1978. Developing a Site Selection Methodology for Wind Energy Conversion Systems. DOE/ET/20280-79/3, National Technical Information Service, Springfield, Virginia.

Troen, I., N. G. Mortensen, and E. L. Petersen. 1988. WAsP Wind Atlas Analysis and Application Programme User's Guide. Riso National Laboratory, Roskilde, Denmark.

Troen, I., and E. L. Petersen. 1989. European Wind Atlas. Risp National Laboratory, Roskilde, Denmark.

Walmsley, J. L., and J. R. Salmon. 1984. "A Boundary-Layer Model for Wind Flow Over Hills: Comparison of Model Results With Askervein 1983 Data." Presented at the European Wind Energy Conference, October 22-26, 1984, Hamburg, Germany.

Walmsley, J. L., P. A. Taylor, and T. Keith. 1986. "A Simple Model of Neutrally Stratified Boundary-Layer Flow Over Complex Terrain With Surface Roughness Modulation (MS3DJH/3R)." Boundary-Layer Meteorol. 36:157-186.

Walmsley, J. L., I. Troen, D. P. Lalas, and P. J. Mason. 1989. "An Intercomparison of Models for Wind Flow in Complex Terrain and Data From the Blashaval Experiment." Presented at the European Wind Energy Conference, July 10-13, 1989, Glasgow, Scotland. 


\section{DISTRIBUTION}

No. of

Copies

OFFSITE

12 DOE Office of Scientific and Technical Information

J. B. Cadogan

U.S. Department of Energy

Wind/Hydro/Ocean Division

1000 Independence Avenue, S.W.

Forrestal Building, Room 5F064

Washington, DC 20585

B. Armstrong

Seawest Industries

1455 Frazee Road, Suite 300

San Diego, CA 92108

B. Bailey

Associated Weather Services

55 Colvin Avenue

Albany, NY 12206

R. Baker

3778 Wisteria Way

Corvallis, OR 97330

S. Blake

WINDUSTRIES, Inc.

P.0. Box 1006

Fairfield, IA 52556

N. Butler

Bonneville Power Administration

P.0. Box 3621

Portland, OR 97208

J. R. Connell

Colorado State University

Engineering Research Center

Foothills Campus

Fort Collins, CO 80523

K. Cousineau

Zond Systems Incorporated

13000 Jameson Road

Tehachapi, CA 93561
No. of

Copies

E. Davis

U.S. Windpower

6952 Preston Avenue

Livermore, CA 94550

D. Foster

Aerovironment, Inc.

825 Myrt le Avenue

Monrovia, CA 91016-3424

S. Hock

Solar Energy Research Institute

1617 Cole Boulevard

Golden, CO 80401

S. Holets

Pacific Gas \& Electric Company

215 Market Street, Rm. 454

San Francisco, CA 94106

J. Kline

456 Larchwood Place

Oakley, CA 94561

P. B. S. Lissaman

Aerovironment, Inc .

825 Myrt le Avenue

Monrovia, CA 91016-3424

R. Lynette

R. Lynette and Associates, Inc.

15032 N.E. 40th Street, Sujte 206

Redmond, WA 98052

E. McCarthy

U.S. Windpower

6952 Preston Avenue

Livermore, CA 94550

A. H. Miller

10013 Tepopa Drive

Oakdale, CA 95361

R. Nierenberg

153 Sacramento Avenue

San Anselmo, CA 94960 
No. of

Copies

M. Sacarny

Second Wind, Inc.

7 Davis Square

Somerville, MA 02144

L. Schienbein

Flowind Corporation

1183 Quarry Lane

Pleasanton, CA 94566

R. Simon

434 0akdale Avenue

Corte Madera, CA 94925

D. Suehiro

HERS

P.0. Box 730

Honolulu, HI 96808

R. Thresher

Solar Energy Research Institute

1617 Cole Boulevard

Golden, CO 80401

W. A. Vachon

W. A. Vachon \& Associates, Inc.

P.0. Box 149

Manchester, MA 01944

S. Veenhuizen

United Industries Corp.

12835 Bel-Red Road

Bellevue, WA 98005

P. Veers

Sandia National Laboratories

Division 6225

Albuquerque, NM 87185
No. of

Copies

J. Wade

Pacific Wind Energy

P.0. Box 1671

Corvallis, OR 97339

S. N. Walker

Department of Mechanical

Engineering

Oregon State University

Corvallis, OR 97331

\section{ONSITE}

DOE Richland Operations Office

E. C. Norman/R. B. Goranson

31 Pacific Northwest Laboratory

J. C. Barnard (10)

D. L. Elliott

J. W. Falco

G. L. Gower

J. M. Hales

P. C. Hays

V. R. Morris

W. R. Pennell

E. L. Owczarski

R. L. Skaggs

L. L. Wendell (6)

Publishing Coordination

Technical Report Files 